\title{
Guidance for the practical management of the direct oral anticoagulants (DOACs) in VTE treatment
}

\author{
Allison E. Burnett ${ }^{1} \cdot$ Charles E. Mahan $^{2} \cdot$ Sara R. Vazquez $^{3} \cdot$ Lynn B. Oertel $^{4}$ • \\ David A. Garcia ${ }^{5} \cdot$ Jack Ansell $^{6}$
}

Published online: 16 January 2016

(c) The Author(s) 2016. This article is published with open access at Springerlink.com

\begin{abstract}
Venous thromboembolism (VTE) is a serious medical condition associated withsignificant morbidity and mortality, and an incidence that is expected to double in thenext forty years. The advent of direct oral anticoagulants (DOACs) has catalyzedsignificant changes in the therapeutic landscape of VTE treatment. As such, it isimperative that clinicians become familiar with and appropriately implement newtreatment paradigms. This manuscript, initiated by the Anticoagulation Forum, providesclinical guidance for VTE treatment with the DOACs. When possible, guidancestatements are supported by existing published evidence and guidelines. In instanceswhere evidence or guidelines are lacking, guidance statements represent theconsensus opinion of all authors of this manuscript and are endorsed by the Board ofDirectors of the Anticoagulation Forum.

The authors of this manuscript first developed a list of pivotal practical questions relatedto real-world clinical
\end{abstract}

Allison E. Burnett

aburnett@salud.unm.edu

1 University of New Mexico Hospital Inpatient Antithrombosis Service, University of New Mexico College of Pharmacy, 2211 Lomas Blvd. NE, Albuquerque, NM 87106, USA

2 Presbyterian Healthcare Services, University of New Mexico College of Pharmacy, Albuquerque, NM, USA

3 University of Utah Health Care Thrombosis Center, Salt Lake City, UT, USA

4 Anticoagulation Management Service, Massachusetts General Hospital, Boston, MA, USA

5 Division of Hematology, University of Washington School of Medicine, Seattle, WA, USA

6 Hofstra North Shore/LIJ School of Medicine, Hempstead, NY, USA scenarios involving the use of DOACs for VTE treatment. We thenperformed a PubMed search for topics and key words including, but not limited to,apixaban, antidote, bridging, cancer, care transitions, dabigatran, direct oralanticoagulant, deep vein thrombosis, edoxaban, interactions, measurement, perioperative,pregnancy, pulmonary embolism, reversal, rivaroxaban, switching,thrombophilia, venous thromboembolism, and warfarin to answer these questions. Non-English publications and publications $>10$ years old were excluded. In an effort toprovide practical information about the use of DOACs for VTE treatment, answers toeach question are provided in the form of guidance statements, with the intent of highutility and applicability for frontline clinicians across a multitude of care settings.

Keywords DOACs $\cdot$ NOACs $\cdot$ Direct thrombin inhibitors · Factor Xa inhibitors · Antidotes · Care transitions · Bridging anticoagulation - Drug interactions

\section{Introduction}

The availability of the new direct oral anticoagulants (DOACs) has significantly changed the therapeutic landscape of anticoagulation and these agents may eventually displace conventional VTE treatment with a rapid-acting parenteral anticoagulant overlapped with a vitamin $\mathrm{K}$ antagonist (e.g. warfarin) in appropriately selected patients. As a class, the DOACs exhibit comparable efficacy and a significantly lower bleeding risk compared to warfarin among patients with acute symptomatic VTE [1, 2]. For patients who need extended anticoagulation for secondary VTE prevention, the safety record of the DOACs is strong [3-5].

In this paper we will examine key questions pertaining to the practical management of DOACs for VTE treatment, 
summarize the evidence (where it exists) pertaining to those questions, and finally, provide guidance that may be applied to real-world practice by frontline clinicians.

\section{Methods}

To provide guidance on the practical management of the DOACs, we first developed a number of pivotal practical questions that apply to DOACs as they might be used in the treatment of VTE. (Table 1). Questions were developed by consensus of the authors. The medical literature was reviewed using PubMed for topics and key words including, but not limited to, adherence, anticoagulant, apixaban, appropriate patient selection, bleed, bridging, care transitions, adherence, CYP, dabigatran, deep venous thrombosis (DVT), direct, edoxaban, education, follow-up, hemorrhage, initiation, interaction, measurement, monitoring, novel, oral, peri-operative, p-glycoprotein, practical management, prothrombin complex concentrate (PCC) pulmonary embolism (PE), reversal, rivaroxaban, safety, switching, target-specific, temporary interruption (TI), and venous thromboembolism (VTE). Non-English language publications and publications $>10$ years old were excluded. Guidance provided in this document is, whenever possible, based on the best available evidence. For some issues, however, published evidence is lacking. In all instances, guidance statements represent the consensus opinion(s) of all authors and are endorsed by the Anticoagulation Forum's Board of Directors.

\section{Guidance}

1. Which VTE patients are (and are not) good candidates for DOAC therapy?

The DOACs have been studied extensively in clinical trials and the results demonstrate they are at least as safe and effective as conventional treatment in the majority of typical VTE patients. However, many specific subgroups were excluded or underrepresented in these studies and the safety and efficacy of DOACs within these subgroups has yet to be established. The inclusion criteria for the VTE treatment trials included patients age $\geq 18$ (no pediatric studies have been published) with an acute symptomatic proximal DVT and/or PE. Exclusion criteria varied slightly among the trials, but in general, patients were excluded if they had any of the following: need for thrombolytic therapy, another indication for anticoagulation, high risk of bleeding, clinically significant liver disease (acute or chronic hepatitis, cirrhosis, or alanine aminotransferase level greater than three times the upper limit of normal),
Table 1 Guidance questions to be considered

1. Which VTE patients are (and are not) good candidates for DOAC therapy?

2. How should DOACs be initiated for VTE treatment?

3. How should the anticoagulant activity of DOACs be measured?

4. How should VTE patients who require temporary interruption of DOAC therapy be managed?

5. How should patients with DOAC drug-drug interactions be managed?

6. How should patients transition between anticoagulants?

7. How should DOAC-associated bleeding be managed?

8. What is an appropriate care transitions and follow-up strategy for VTE patients on DOAC therapy?

9. How can patients enhance safety and efficacy of their DOAC therapy?

Table 2 Potential advantages and disadvantages of DOACs compared to VKAs [119]

\begin{tabular}{|c|c|}
\hline Advantages & Disadvantages \\
\hline No routine monitoring & $\begin{array}{l}\text { No reliable, readily available } \\
\text { measurement assay }\end{array}$ \\
\hline Improved safety profile & $\begin{array}{l}\text { Dose reduction or avoidance in } \\
\text { renal impairment and } \\
\text { avoidance in moderate or } \\
\text { severe hepatic impairment }\end{array}$ \\
\hline $\begin{array}{l}\text { Rapid onset (may preclude the } \\
\text { need for induction or bridging } \\
\text { therapy) }\end{array}$ & No specific antidote \\
\hline $\begin{array}{l}\text { Short half-life (advantageous for } \\
\text { invasive procedures or in the } \\
\text { setting of active bleed) }\end{array}$ & $\begin{array}{l}\text { Short half-life (mandates strict } \\
\text { adherence) }\end{array}$ \\
\hline Fixed dosing & Less flexibility in dosing \\
\hline $\begin{array}{l}\text { Greater convenience, patient } \\
\text { satisfaction and quality of life }\end{array}$ & $\begin{array}{l}\text { Fewer studies and approved } \\
\text { indications (e.g., } \\
\text { contraindicated in mechanical } \\
\text { valve replacement) }\end{array}$ \\
\hline $\begin{array}{l}\text { Potentially more cost-effective } \\
\text { from health system perspective }\end{array}$ & $\begin{array}{l}\text { Potentially higher drug } \\
\text { acquisition costs for patients }\end{array}$ \\
\hline $\begin{array}{l}\text { Fewer drug, disease and diet } \\
\text { interactions }\end{array}$ & $\begin{array}{l}\text { DOAC drug interactions do exist } \\
\text { that may preclude use }\end{array}$ \\
\hline
\end{tabular}

creatinine clearance $(\mathrm{CrCl})<30 \mathrm{~mL} / \mathrm{min}$ (for apixaban the threshold was $25 \mathrm{~mL} / \mathrm{min}$ ), life expectancy of $<3-6$ months, aspirin use $>100 \mathrm{mg} /$ day, using interacting medications, uncontrolled hypertension, breastfeeding or pregnant or of childbearing potential without appropriate contraceptive measures [3-10]. Table 2 represents potential advantages and disadvantages of DOACs in comparison to conventional therapy that should be considered by both clinicians and patients before deciding on an anticoagulant regimen. Table 3 provides selection criteria for patients suitable for DOAC therapy. Table 4 provides further considerations regarding patient-controlled aspects, 
Table 3 DOAC patient selection criteria

\begin{tabular}{|c|c|}
\hline Criteria for DOAC use & Comment(s) \\
\hline Patient preference for and willingness to take DOAC & $\begin{array}{l}\text { Patients should be presented will all therapeutic options and their } \\
\text { respective perceived advantages and disadvantages (See Table 2) }\end{array}$ \\
\hline No contraindication to DOAC therapy & E.g. pregnancy, breastfeeding, mechanical heart valve \\
\hline Adequate organ function & $\begin{array}{l}\text { Clinicians should regularly monitor renal function, particularly for DOACs } \\
\text { with greater reliance on renal elimination (see Tables 5, } 6 \text { and 12) and, if } \\
\text { there are other factors that may increase DOAC exposure (e.g. age, } \\
\text { unavoidable use of concomitant p-gp/CYP3A4 inhibitors). Avoid in } \\
\text { moderate or severe hepatic dysfunction }\end{array}$ \\
\hline \multirow[t]{2}{*}{ No significant drug-drug interactions } & See Tables 13 and 14 for detailed guidance \\
\hline & $\begin{array}{l}\text { Patients taking any anticoagulant with antiplatelet agents or NSAIDs have } \\
\text { a significantly higher risk of bleeding. To minimize bleeding, avoid these } \\
\text { drug combinations when possible }\end{array}$ \\
\hline No significant disease state interactions & $\begin{array}{l}\text { VTE patients with a history of GI bleeding or at risk for GI bleeding may } \\
\text { be better candidates for warfarin, apixaban, or edoxaban, as there may be } \\
\text { a higher risk of bleeding or GI adverse effects with dabigatran and } \\
\text { rivaroxaban }\end{array}$ \\
\hline $\begin{array}{l}\text { Highly likely to be adherent with DOAC therapy and follow-up } \\
\text { plan }\end{array}$ & See Table 4 for further details \\
\hline \multirow[t]{2}{*}{$\begin{array}{l}\text { Confirmed ability to obtain DOAC on a longitudinal basis from a } \\
\text { financial, insurance coverage and retail availability standpoint }\end{array}$} & $\begin{array}{l}\text { The drug costs of DOACs may be prohibitive for some patients, as } \\
\text { compared with generic warfarin plus laboratory monitoring }\end{array}$ \\
\hline & $\begin{array}{l}\text { There are patient assistance programs available via the pharmaceutical } \\
\text { companies, and this should be arranged prior to prescribing }\end{array}$ \\
\hline
\end{tabular}

such as adherence, values and preferences as each of these will have a direct impact on outcomes with DOAC therapy.

\section{Pregnancy and breastfeeding}

Animal studies of dabigatran and rivaroxaban demonstrated pregnancy loss and fetal harm [11, 12], and one study demonstrated that dabigatran does cross the human placenta [13]. A case report of maternal rivaroxaban use during weeks 1-19 of pregnancy (when pregnancy discovered at week 19, the patient was switched to enoxaparin) resulted in a full-term, low growth percentile, otherwise healthy infant [14]. Apixaban has no human data in pregnancy, but showed no maternal or fetal harm in animal studies [15]. Edoxaban animal studies demonstrated no fetal harm. The edoxaban VTE treatment trial reported 10 pregnancies, with edoxaban exposure during the first 6 weeks of gestation ( 4 full-term births, 2 pre-term births, 1 first-trimester spontaneous abortion, and 3 elective pregnancy terminations) [16]. It is unknown whether any of the DOACs are excreted in breast milk. Because of the potential for infant harm, a decision should be made to either avoid breastfeeding or use an alternative anticoagulant, such as warfarin, in these women.

\section{Body weight extremes}

Patients at extremes of weight represented a very small proportion of subjects in DOAC VTE treatment trials. [310]. The mean weight was around $84 \mathrm{~kg}$, with the majority of patients weighing between 60 and $100 \mathrm{~kg}$. Underweight patients $(<50-60 \mathrm{~kg})$ comprised $2-13 \%$ of the study populations and roughly $14-19 \%$ of patients were $>100 \mathrm{~kg}$. Approximately $30 \%$ of patients in the EINSTEIN, AMPLIFY and RE-COVER studies had a $\mathrm{BMI} \geq 30 \mathrm{~kg} / \mathrm{m}^{2}$, and in the AMPLIFY and RE-COVER studies, only $12 \%$ of subjects had a BMI $\geq 35 \mathrm{~kg} / \mathrm{m}^{2}$. Based on very limited data, extremes of weight do not appear to affect peak concentrations or bioavailability of dabigatran [17]. The pharmacokinetics and pharmacodynamics of factor Xa inhibitors may be affected by weight [10, 15, 18-20], but the clinical impact of these effects remains unknown. Pending further evidence in patients at extremes of weight (e.g., $<50 \mathrm{~kg}, \quad>120 \mathrm{~kg}$ or $\mathrm{BMI} \geq 35 \mathrm{~kg} / \mathrm{m}^{2}$ ) it is advisable to limit DOAC use to situations where vitamin $\mathrm{K}$ antagonists cannot be used.

\section{Thrombophilia}

Patients with thrombophilias represented 2-18\% of DOAC VTE clinical trial populations [3-9]. A posthoc subgroup analysis of thrombophilia patients within the REMEDY trial was recently presented [21]. Results showed that the frequencies of VTE-related death and PE did not differ between dabigatran and warfarin patients. The authors concluded that dabigatran's efficacy in preventing recurrent VTE is not influenced by the presence of thrombophilia. Conversely, six cases citing possible failure of rivaroxaban or dabigatran to prevent thrombosis in patients with antiphospholipid antibody syndrome were recently published $[22,23]$. While it is possible the DOACs 
Table 4 Patient adherence assessments when choosing anticoagulant therapies [118-123]

\begin{tabular}{|c|c|}
\hline Taking medications & $\begin{array}{l}\text { How often does the patient miss or forget to take doses of their medication(s)? } \\
\text { - If a warfarin patient frequently misses doses, switching to a shorter half-life DOAC may more rapidly predispose the } \\
\text { patient to risk of thrombosis } \\
\text { - Often, a subtherapeutic INR is a reliable indicator to the clinician and patient that warfarin doses have been missed } \\
\text { - Without the requirement for laboratory monitoring with the DOACs, there is no such alert to indicate opportunities to } \\
\text { improve adherence } \\
\text { Is a once-daily or a twice-daily medication dosing frequency preferred? } \\
\text { - If patient is adherent with other twice daily medications, any of the DOACs may be appropriate } \\
\text { - Conversely, if patient prefers once daily medications, rivaroxaban or edoxaban may be preferred }\end{array}$ \\
\hline $\begin{array}{l}\text { Laboratory } \\
\text { monitoring }\end{array}$ & $\begin{array}{l}\text { Is laboratory access difficult? } \\
\text { - Patients with transportation challenges, difficult venous access, inflexible work or school schedules or other reasons } \\
\text { for difficulty complying with INR monitoring may significantly benefit from DOAC therapy } \\
\text { - Clinicians should remind DOAC patients that renal function and a complete blood count should be monitored at least } \\
\text { annually or more frequently as the clinical situation dictates }\end{array}$ \\
\hline $\begin{array}{l}\text { Health care } \\
\text { responsibility }\end{array}$ & $\begin{array}{l}\text { Is the patient reliable to notify health care providers about changes to health and pertinent medical issues? } \\
\text { - It is important for the patient to make all health care providers aware he or she is taking an anticoagulant medication, } \\
\text { as this information will aid in: } \\
\text { - design of peri-procedural anticoagulation plans } \\
\text { - addressing medication interactions } \\
\text { - consideration of other health status changes } \\
\text { - Patients who may be unreliable to report pertinent issues to the clinician may be better suited to warfarin so that at } \\
\text { least some of these may be uncovered during INR follow-up } \\
\text { - DOAC patients and their clinicians may elect to interact via clinic visit, phone, or electronic media at a regular } \\
\text { interval }\end{array}$ \\
\hline
\end{tabular}

$I N R$ International normalized ratio, DOAC direct oral anticoagulant

Table 5 Drug characteristics to consider when deciding which DOAC to prescribe for VTE [3-12, 15, 16]

\begin{tabular}{lllllll}
\hline DOAC & $\begin{array}{l}\text { Parenteral } \\
\text { lead-in }\end{array}$ & $\begin{array}{l}\text { Single-drug } \\
\text { approach }\end{array}$ & $\begin{array}{l}\text { Switch or dose } \\
\text { de-escalation }\end{array}$ & Dosing frequency & $\begin{array}{l}\text { Renal } \\
\text { elimination }\end{array}$ & $\begin{array}{l}\text { Potential for increased } \\
\text { adverse effects }\end{array}$ \\
\hline Dabigatran & $\sqrt{ }$ & & $\sqrt{ }$ & BID & ++++ & MI, GIB, dyspepsia \\
Rivaroxaban & & $\sqrt{ }$ & $\sqrt{ }$ & BID $\times 21$ days, then once daily & ++ & GIB \\
Apixaban & & $\sqrt{ }$ & $\sqrt{ }$ & BID & + & N/A \\
Edoxaban & $\sqrt{ }$ & & $\sqrt{ }$ & Once daily & ++ & N/A \\
\hline
\end{tabular}

$B I D$ twice daily, $G I B$ gastrointestinal bleed, $M I$ myocardial infarction

may be a viable option for VTE treatment in patients with weaker underlying thrombophilias (e.g., heterozygous Factor V Leiden), caution or avoidance, especially in highly pro-thrombotic states such as antiphospholipid antibody syndrome or heparin-induced thrombocytopenia, is suggested until further evidence becomes available.

\section{Cancer}

Four meta-analyses of DOAC VTE clinical trials including approximately 1000 cancer patients (patients with a history of cancer or some with active cancer) demonstrated similar efficacy and safety for the DOACs compared to conventional therapy of a vitamin $\mathrm{K}$ antagonist overlapped with LMWH [24-27]. Previous trials, which included approximately 2000 patients with active cancer (many in advanced stages), indicate that vitamin $\mathrm{K}$ antagonists are inferior to long-term LMWH monotherapy for treatment of cancer-related VTE [28-31]. While most evidence to date is with dalteparin, the recent $\mathrm{CATCH}$ study [32] showing a trend $(p=0.07)$ towards superiority of tinzaparin over warfarin for prevention of recurrent symptomatic DVT and reduction in clinically relevant non-major bleeding suggests this may be a class effect of the LMWHs. Whether DOACs convey similar benefit as LMWH monotherapy for 
VTE treatment in cancer patients remains unknown. Data from head-to-head randomized controlled trials or robust comparative effectiveness studies is needed and future research in this area is encouraged. Until then, among patients with cancer-associated VTE, long-term LMWH is the preferred first-line therapy for anticoagulant treatment (see chapter by Khorana et al.). However, for those patients who cannot (or will not) use long term LMWH, either a DOAC or VKA could be prescribed as a second-line option. Given their improved safety profile compared to warfarin, DOACs may well be preferred in these instances, particularly among patients with a perceived increased risk for bleeding. However, it is important to emphasize the lack of experience with DOACs compared to warfarin in cancer patients who may have profound thrombocytopenia and other clinical challenges pertaining to anticoagulation. The lack of readily available measurement assays for DOACs may be particularly problematic in the setting of drug interactions, nephrotoxic chemotherapy, and potential disruption in absorption due to short gut or malnutrition, common issues in a cancer population.

\section{History of bleeding}

Much of the available data on DOACs and gastrointestinal (GI) bleeding is from atrial fibrillation trials, which generally consisted of older patients with more comorbidities than the VTE treatment populations. In a real- world study of Medicare claims data among new users of dabigatran or warfarin for non-valvular atrial fibrillation [33], there was a $28 \%$ overall increased risk for gastrointestinal bleeding among dabigatran patients compared to warfarin patients. This was most pronounced in women $\geq 75$ years of age (HR 1.5; $95 \%$ CI 1.2-1.88), men $\geq 85$ years of age (HR $1.55 ; 95 \%$ CI 1.04-2.32) and in patients receiving the higher dose of $150 \mathrm{mg}$ twice daily (HR 1.51; $95 \%$ CI 1.32-1.73). A meta-analysis of 4 dabigatran trials of both NVAF and VTE treatment reported a $41 \%$ increase in the risk of GI bleeding with dabigatran [34]. In the individual DOAC VTE treatment trials [3-10], GI bleeding event rates were too low to draw definite conclusions (dabigatran and rivaroxaban numerically higher rates of GI bleeding, apixaban and edoxaban numerically lower rate of GI bleeding) compared to conventional anticoagulation therapy. A meta-analysis of data from 11 phase-3 DOAC NVAF or VTE treatment trials found no significant difference in major gastrointestinal bleeding between DOACs and warfarin (2.09 vs. $1.7 \%$; RR 0.94; $95 \%$ CI 0.75-1.99; $p=0.62, \mathrm{I}^{2} 71 \%$ ) [35]. Even so, careful consideration should be exercised in regards to DOAC use in patients with a history of gastrointestinal bleeding.

Intracranial hemorrhage (ICH) is the most feared complication of anticoagulant therapy. A significant advance with DOAC therapy over warfarin has been a reduction in the rates of $\mathrm{ICH}$ in atrial fibrillation. Numerically lower rates of both $\mathrm{ICH}$ and fatal bleeding were seen in all DOAC arms of the VTE trials [3-10], with the exception of intracranial hemorrhage in the EINSTEIN-DVT trial (2 events in the rivaroxaban arm vs. none in the warfarin arm) [4]. A systematic review and meta-analysis of 12 randomized controlled trials including over 100,000 patients with either NVAF or VTE showed that DOACs are associated with less major bleeding, fatal bleeding, intracranial bleeding, clinically relevant non-major bleeding, and total bleeding compared to warfarin [35]. This provides a compelling argument to favor these agents over conventional therapy for VTE treatment whenever possible.

Guidance statement DOACs are suggested as an alternative to conventional therapy for VTE treatment in patients who meet appropriate patient selection criteria. For all other patients, we suggest VTE treatment with conventional therapy. Until further data are available, we suggest avoiding DOACs for VTE in patients with antiphospholipid antibody syndrome and patients at extremes of weight. LMWH monotherapy remains first line for patients with cancer-related VTE, but DOACs may be considered in select patients unwilling or unable to receive subcutaneous injections.

\section{How should DOACs be initiated for VTE treatment?}

Before prescribing a DOAC, a thorough evaluation should be conducted to ensure the patient is a good candidate for DOAC therapy, as detailed in Tables 3 and 4. Baseline labs should be performed, including serum creatinine, liver function tests, complete blood count, and coagulation assays such as aPTT and PT to ensure adequate organ function and rule out coagulopathy. In general, DOAC therapy should not be initiated in patients presenting with extensive VTE if there is potential need for an invasive procedure, such as thrombolysis or thrombectomy. Instead, preference should be given to a shorter-acting, reversible agent such as unfractionated heparin until no further immediate procedures are needed. Clinicians should consider characteristics of the individual agents when selecting which DOAC to initiate (detailed in Table 5). In addition, concomitant drug therapies and comorbidities should also be accounted for in DOAC dose management as detailed in Table 6. In clinical trials of edoxaban and dabigatran [6, 10] initial treatment consisted of open-label parenteral anticoagulation (median of 9 and 7 days in the dabigatran and edoxaban trials, respectively) overlapped with warfarin titrated to an INR of 2-3 in the control arm or overlapped with warfarin-placebo titrated to a sham INR in the intervention arms. Concomitant administration of a parenteral anticoagulant and a DOAC was not employed in either of 
Table 6 Dosing of DOACs for VTE treatment [3-12, 15, 16]

\begin{tabular}{|c|c|c|c|c|}
\hline & Dabigatran & Rivaroxaban & Apixaban & Edoxaban \\
\hline Acute VTE & $\begin{array}{l}150 \mathrm{mg} \text { BID after } \\
\geq 5 \text { days of parenteral } \\
\text { anticoagulation }\end{array}$ & $\begin{array}{l}15 \mathrm{mg} \text { BID with } \\
\text { food } \times 3 \text { weeks then } \\
20 \mathrm{mg} \text { once daily with } \\
\text { food }\end{array}$ & $\begin{array}{l}10 \mathrm{mg} \text { BID for } 7 \text { days, then } 5 \mathrm{mg} \\
\text { BID }\end{array}$ & $\begin{array}{l}60 \mathrm{mg} \text { once daily after } \\
\geq 5 \text { days of parenteral } \\
\text { anticoagulation }\end{array}$ \\
\hline $\begin{array}{l}\text { Prevention of VTE } \\
\text { recurrence }\end{array}$ & No dose adjustment & No dose adjustment & $\begin{array}{l}\text { Decrease to } 2.5 \mathrm{mg} \text { BID after at } \\
\text { least } 6 \text { months of therapeutic } \\
\text { anticoagulation }\end{array}$ & Not studied \\
\hline $\begin{array}{l}\text { Dosage adjustments } \\
\text { and/or thresholds } \\
\text { for avoidance }\end{array}$ & $\begin{array}{l}\text { Any } \mathrm{P} \text {-gp inducer: avoid } \\
\text { concurrent use } \\
\text { Any } \mathrm{P} \text {-gp inhibitor with } \\
\mathrm{CrCl}<50 \mathrm{~mL} / \mathrm{min}: \\
\text { avoid concurrent use } \\
\mathrm{CrCl}<30 \mathrm{~mL} / \mathrm{min} \text { : avoid } \\
\text { use }\end{array}$ & $\begin{array}{l}\mathrm{CrCl}<30 \mathrm{~mL} / \mathrm{min} \text { : avoid } \\
\text { use } \\
\text { Dual strong CYP3A4 and } \\
\text { P-gp inhibitors or } \\
\text { inducers: avoid use }\end{array}$ & $\begin{array}{l}\text { Dual strong CYP3A4 and P-gp } \\
\text { inducers: avoid use } \\
\text { Dual strong CYP3A4 and P-gp } \\
\text { inhibitors: } \\
\text { If dose }>2.5 \mathrm{mg} \text { BID, decrease } \\
\text { dose by } 50 \% \\
\text { If already taking } 2.5 \mathrm{mg} \text { BID and } \\
\text { dual strong CYP3A4 and P-gp } \\
\text { inhibitor: avoid use } \\
\text { No dose adjustment for renal } \\
\text { impairment provided }\end{array}$ & $\begin{array}{l}30 \mathrm{mg} \text { once daily if any } \\
\text { of the following: } \\
\mathrm{CrCl} 15-50 \mathrm{~mL} / \mathrm{min} \\
\text { Weight }<60 \mathrm{~kg} \\
\text { Concomitant } \mathrm{P}-\mathrm{gp} \\
\text { inhibitor } \\
\mathrm{CrCl}<15 \mathrm{~mL} / \mathrm{min}: \\
\text { avoid use }\end{array}$ \\
\hline
\end{tabular}

$D O A C$ direct-acting oral anticoagulant, $V T E$ venous thromboembolism, $B I D$ twice daily, $P$ - $g p$ P-glycoprotein, $C r C l$ creatinine clearance, CYP3A4 cytochrome P-450 3A4

these trials, as that would likely lead to excessive anticoagulation based on the rapid onset of the DOACs. Dabigatran was initiated at $150 \mathrm{mg}$ BID. Edoxaban was initiated at $60 \mathrm{mg}$ once daily, with a dose reduction to $30 \mathrm{mg}$ once daily in patients with a creatinine clearance of $30-50 \mathrm{~mL} / \mathrm{min}$ or a body weight of $60 \mathrm{~kg}$ or less or in patients who were receiving concomitant treatment with potent P-glycoprotein inhibitors. Package labelling for dabigatran and edoxaban also indicates the required 5-10 days of parenteral anticoagulation prior to their initiation for acute VTE, which closely approximates the conventional approach to VTE treatment.

For patients with acute VTE selected for treatment with edoxaban or dabigatran, for lead-in therapy we suggest use of subcutaneous (SC) anticoagulants LMWH or fondaparinux over unfractionated heparin (UFH) when possible due to improved safety and efficacy $[36,37]$ and facilitation of outpatient therapy in eligible patients. (See care transitions section for more details). When switching from lead-in parenteral therapy within the acute VTE treatment phase, edoxaban or dabigatran should be initiated at the time that a heparin infusion is discontinued or the time the next dose of SC anticoagulant is due.

In clinical trials of apixaban [5] and rivaroxaban [4, 8], a single-drug approach was employed without parenteral anticoagulation. A higher dose was used in the initial period followed by a dose reduction(s). Apixaban was initiated with $10 \mathrm{mg}$ BID for the first 7 days and reduced to $5 \mathrm{mg}$ BID thereafter. Rivaroxaban was initiated at $15 \mathrm{mg}$ BID for 21 days followed by $20 \mathrm{mg}$ once daily. Less than
$2 \%$ of patients in apixaban and rivaroxaban VTE treatment trials received $>2$ days of parenteral anticoagulation before randomization which reinforces that these agents can be safely used as an oral, single-drug strategy for VTE treatment. Rivaroxaban and apixaban monotherapy should be initiated as soon as it is determined that no invasive procedures are needed. If the patient has been receiving empiric or temporary UFH or SC anticoagulant therapy for acute treatment of VTE, apixaban or rivaroxaban should be initiated at the time that the heparin infusion is discontinued or at the time the next dose of SC anticoagulant is due.

Guidance statement We suggest that a thorough patient evaluation be conducted prior to DOAC initiation which should include assessment of baseline laboratory values, concomitant drug therapies, and comorbidities. We do not recommend initial DOAC therapy in patients who are hospitalized with extensive DVT or who have PE with hemodynamic instability in whom thrombolysis or thrombectomy may be indicated. We suggest that the unique characteristics of each DOAC, their distinct dosing for VTE treatment, and patient preferences should be considered when selecting a DOAC for VTE treatment.

3. How should the anticoagulant activity of DOACs be measured?

The specificity, predictability and wide therapeutic index of the DOACs allow for fixed dosing without a need for routine monitoring. However, there are instances during 
Table 7 Potential indications for DOAC measurement [38-40]

\begin{tabular}{lll}
\hline Detection of clinically relevant levels & Detection of expected on-therapy levels & Detection of excessive levels \\
\hline Urgent or emergent invasive procedure & Assessing adherence & Hemorrhage \\
Neuraxial anesthesia & Breakthrough thrombosis & Diminished/changing renal function \\
Major trauma & & Hepatic impairment \\
Potential thrombolysis in acute thromboembolism & & Accidental or intended overdose \\
Hemorrhage & & Drug interactions \\
& & Advanced age
\end{tabular}

Table 8 Suggestions for laboratory measurement of DOACs [40]

\begin{tabular}{|c|c|c|c|c|c|c|}
\hline \multicolumn{7}{|c|}{ Clinical objective } \\
\hline \multirow[t]{2}{*}{ Drug } & \multicolumn{2}{|c|}{$\begin{array}{l}\text { Determine if clinically relevant below on- } \\
\text { therapy drug levels are present }\end{array}$} & \multicolumn{2}{|c|}{$\begin{array}{l}\text { Estimate drug levels } \\
\text { within on-therapy range }\end{array}$} & \multicolumn{2}{|c|}{ Determine if above on-therapy drug levels are present } \\
\hline & $\begin{array}{l}\text { Suggested } \\
\text { test }\end{array}$ & Interpretation & $\begin{array}{l}\text { Suggested } \\
\text { test }\end{array}$ & Interpretation & $\begin{array}{l}\text { Suggested } \\
\text { test }\end{array}$ & Interpretation \\
\hline Dabigatran & TT & $\begin{array}{l}\text { Normal TT likely excludes } \\
\text { clinically relevant drug } \\
\text { levels }\end{array}$ & $\begin{array}{l}\text { Dilute TT, } \\
\text { ECA, } \\
\text { ECT }\end{array}$ & & $\begin{array}{l}\text { aPTT, } \\
\text { dilute TT, } \\
\text { ECA, } \\
\text { ECT }\end{array}$ & $\begin{array}{l}\text { Normal aPTT likely excludes excess } \\
\text { drug levels; only dilute TT, ECA, and } \\
\text { ECT are suitable for quantitation }\end{array}$ \\
\hline Rivaroxaban & Anti-Xa & $\begin{array}{l}\text { Normal anti-Xa activity } \\
\text { likely excludes clinically } \\
\text { relevant drug levels }\end{array}$ & Anti-Xa & & $\begin{array}{l}\text { Anti-Xa, } \\
\text { PT }\end{array}$ & $\begin{array}{l}\text { Normal PT likely excludes excess drug } \\
\text { levels; only Anti-Xa is suitable for } \\
\text { quantitation }\end{array}$ \\
\hline Apixaban & Anti-Xa & $\begin{array}{l}\text { Normal anti-Xa activity } \\
\text { likely excludes clinically } \\
\text { relevant drug levels }\end{array}$ & Anti-Xa & & Anti-Xa & $\begin{array}{l}\text { Normal PT may not exclude excess } \\
\text { drug levels; only Anti-Xa is } \\
\text { suitable for quantitation }\end{array}$ \\
\hline Edoxaban & Anti-Xa & $\begin{array}{l}\text { Normal anti-Xa activity } \\
\text { likely excludes clinically } \\
\text { relevant drug levels }\end{array}$ & Anti-Xa & & $\begin{array}{l}\text { Anti-Xa, } \\
\text { PT }\end{array}$ & $\begin{array}{l}\text { Normal PT likely excludes excess drug } \\
\text { levels; only Anti-Xa is suitable for } \\
\text { quantitation }\end{array}$ \\
\hline
\end{tabular}

aPTT Activated partial thromboplastin time, ECA ecarin chromogenic assay, ECT ecarin clotting time, $P T$ prothrombin time, $T T$ thrombin time, need permission from Cuker et al. JACC 2014 [40]

which measurement of DOAC activity would be useful to direct therapy and inform long-term treatment decisions (Table 7) [38-40]. When these situations occur, clinicians need to be familiar with the role, limitations and local availability of various coagulation assays as they relate to DOACs (Tables 7, 8; Fig. 1).

The INR does not vary significantly from hour to hour due to the long half-life of warfarin and the timing of INR in relation to the last warfarin dose is not important. In contrast, the timing of last DOAC dose relative to the coagulation assay is important for interpretation given the relatively short half-life of the DOACs [39]. Most scenarios that would trigger laboratory testing for DOACs are urgent (e.g. bleeding or thrombosis) thus lab results will often be random out of necessity. In the bleeding patient, it is likely sufficient to have a rapidly available quantitative test that will reliably determine whether DOAC is present in measurable quantities (yes or no). In the setting of thrombosis or suspected treatment failure, the ideal test would indicate not only whether drug was present but also if the concentration was consistent with observed ontreatment levels. In the event of concern for DOAC accumulation due to renal insufficiency or drug interactions, trough levels are preferred [39]. For detailed information of the impact of individual DOACs on various anticoagulant assays, please refer to the pharmacology chapter of this compendium by Nutescu et al.

A systematic review regarding laboratory measurement of OAC activity was recently published and provides support for following guidance statements: [40]

Guidance statement We suggest that clinicians do not routinely measure DOAC activity. If measurement of a DOAC is indicated, we suggest that clinicians use assays that are validated either locally or in a reference laboratory and that are readily available. The chosen assay 
Fig. 1 Linearity and specificity of coagulation assays for measurement of DOACs [40]. Reproduced with permission from Cuker et al. [40]

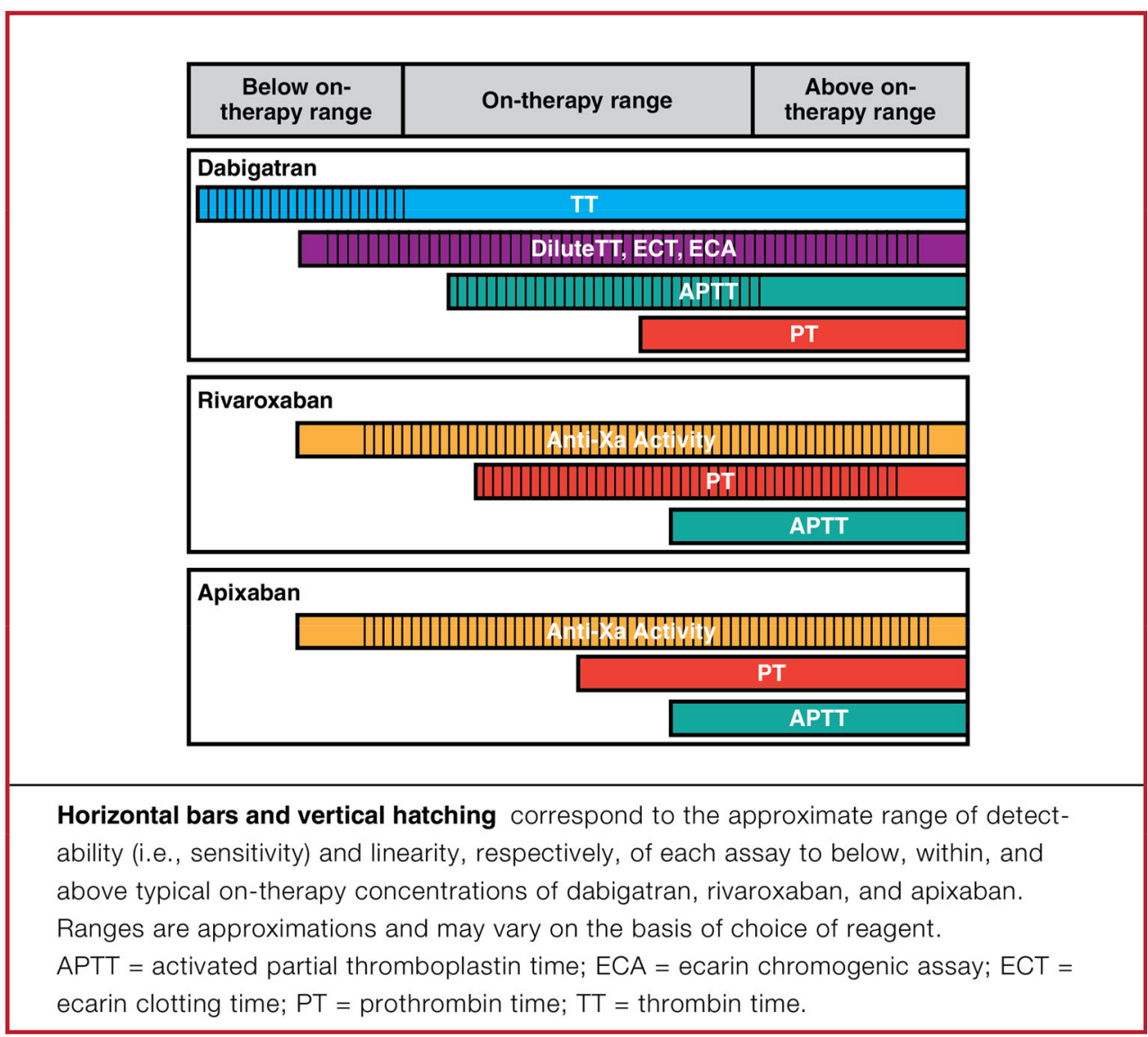

should be suitable for the DOAC being used, as well as for the indication for measurement, as detailed in Table 8.

4. How should VTE patients who require temporary interruption (TI) of DOAC therapy be managed?

\section{Use of bridge therapy}

Approximately $10 \%$ of patients require temporary interruption (TI) of their anticoagulant for a procedure on an annual basis [41] with additional patients requiring interruption due to bleeding or other non-bleeding adverse events [42-44]. Relatively little direct medical literature exists on studies in the VTE treatment population and TI of DOACs; however, some information may be extrapolated from data in other populations as well as guidelines and other practical recommendations. [42-44]. In the RELY and the ROCKET atrial fibrillation (AF) trials, 25 and $33 \%$ of enrolled participants underwent one or more TI during the study period with 17 and $8.2 \%$ utilizing bridging with unfractionated heparin (UFH)/low molecular weight heparin (LMWH) therapy for dabigatran $150 \mathrm{mg}$ and rivaroxaban, respectively [42, 43]. In the RELY trial, there were numerically more bleeding events among dabigatran patients who received bridging therapy compared to warfarin patients receiving bridging therapy (295 for dabigatran $150 \mathrm{mg}$ BID vs. 276 for warfarin). There was no significant difference in the incidence of perioperative major bleeding (4.6 vs. $5.1 \%$ ) or the composite of cardiovascular death, ischemic stroke, and non-central nervous system and pulmonary embolism (1.2 vs. $1.5 \%)$ for warfarin and dabigatran $150 \mathrm{mg}$ BID, respectively. Other bleeding outcomes, including fatal bleeding, bleeding requiring reoperation or transfusion of red blood cells, and minor bleeding were also similar between groups [42]. For rivaroxaban, perioperative major bleeding (0.99\%/30 days vs. $0.79 \% / 30$ days) and the composite of stroke/systemic embolism/myocardial infarction/death (0.66\%/30 days vs. $0.95 \% / 30$ days) were not significantly different for the rivaroxaban and warfarin groups that received bridging therapy, respectively. Overall in the ROCKET AF trial in TI patients, there was numerically higher major/non-major clinically relevant bleeding for those who received bridging therapy versus those who did not (4.83 vs. $3.02 \%$ ) [43]. The data from these subanalyses suggests that bridging therapy with LMWH/UFH should be minimized or avoided in DOAC patients. The pharmacokinetic similarities of these two anticoagulant classes further support avoidance of overlapping therapies to prevent over anticoagulation. 
Table 9 Procedural bleed risk [41, 46, 47]

\begin{tabular}{|c|c|c|}
\hline $\begin{array}{l}\text { MINIMAL bleed risk procedures } \\
\text { that may not require interruption of } \\
\text { anticoagulant therapy }\end{array}$ & $\begin{array}{l}\text { LOW bleeding risk procedures requiring interruption } \\
\text { of anticoagulant therapy }\end{array}$ & $\begin{array}{l}\text { HIGH bleeding risk procedures requiring } \\
\text { interruption of anticoagulant therapy }\end{array}$ \\
\hline $\begin{array}{l}\text { Central venous catheter removal } \\
\text { Dental procedures } \\
\text { Extraction of } 1-2 \text { teeth } \\
\text { Periodontal surgery } \\
\text { Incision of abscess } \\
\text { Implant positioning } \\
\text { Endoscopy without surgery } \\
\text { Ophthalmology } \\
\text { Cataract or glaucoma intervention } \\
\text { Superficial surgery } \\
\text { Abscess incision } \\
\text { Small dermatology excisions }\end{array}$ & $\begin{array}{l}\text { Abdominal hernia repair } \\
\text { Abdominal hysterectomy } \\
\text { Carpal tunnel repair } \\
\text { Cholecystectomy } \\
\text { Dental procedures } \\
\text { Extraction of } 3 \text { or more teeth } \\
\text { Dilatation and curettage } \\
\text { Electrophysiological study or radiofrequency catheter } \\
\text { ablation for supraventricular tachycardia (including } \\
\text { left-sided ablation via single transseptal puncture) } \\
\text { Endoscopy with biopsy or tissue removal } \\
\text { Gastrointestinal endoscopy } \pm \text { biopsy, enteroscopy, } \\
\text { biliary/pancreatic stent without sphincterotomy, } \\
\text { endosonography without fine-needle aspiration } \\
\text { Hemorrhoidal surgery } \\
\text { Hydrocele repair } \\
\text { Non-coronary angiography bronchoscopy } \pm \text { biopsy } \\
\text { Ophthalmology } \\
\text { Non-cataract eye surgery } \\
\text { Prostate or bladder biopsy } \\
\text { Shoulder/foot/hand surgery and arthroscopy }\end{array}$ & 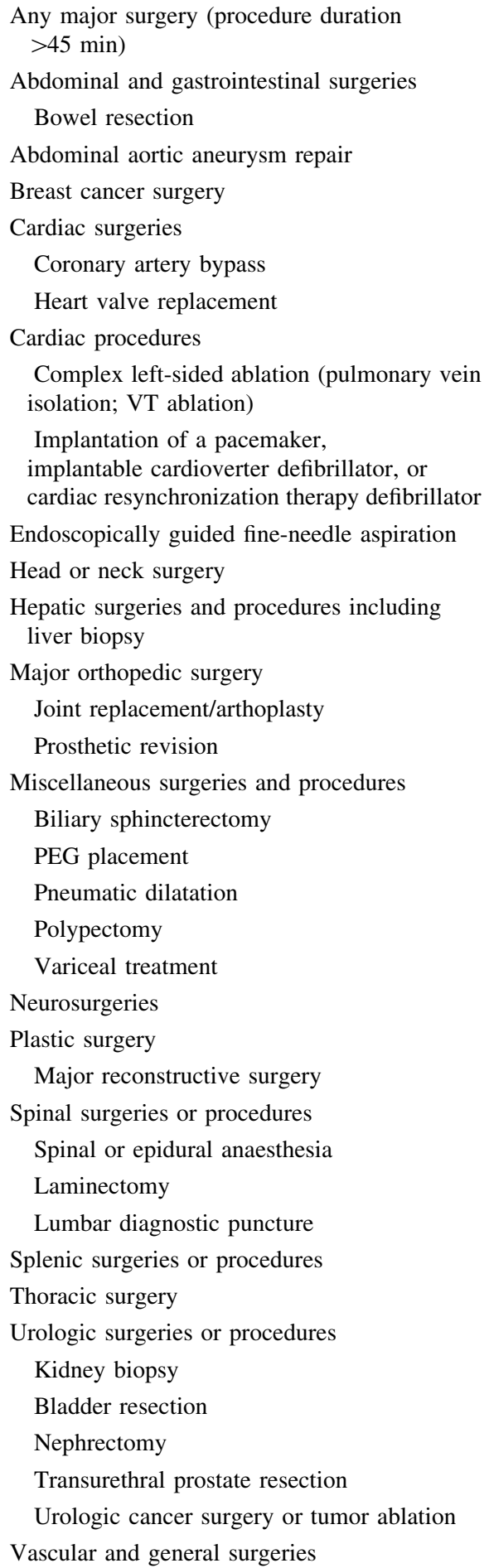 \\
\hline
\end{tabular}

\section{Managing DOAC interruptions for invasive procedures}

Determining the optimal approach to management of DOACs around elective invasive procedures involves addressing a few key clinical questions. For elective procedures, clinicians should first consider whether the procedure can be delayed until a time that the patient may not 
Table 10 Patient-specific risk factors for bleeding [36, 124, 125]

\begin{tabular}{ll}
\hline General risk factors & $\begin{array}{l}\text { Medical patient risk } \\
\text { factors }\end{array}$ \\
\hline Active or metastatic cancer & Age-increasing \\
Age (e.g. $>65$ years) & Active cancer \\
Anemia & Anemia and other blood \\
Comorbidity and reduced functional & dyscrasias \\
capacity & Current liver disease \\
Concomitant medications such as & Central venous catheter \\
NSAIDs, antiplatelets or other & placement \\
anticoagulants administered possibly in & History of bleeding \\
a transition period & Hospital stay of $\geq 3$ days \\
Diabetes & ICU/CCU stay \\
Alcohol abuse & Male gender \\
Frequent falls & Previous or active \\
Hepatic or renal dysfunction & gastroduodenal ulcer \\
History of bleeding complications & Thromboembolic stroke \\
Previous stroke & Recent re-hospitalization \\
Recent surgery & Renal failure \\
Thrombocytopenia & Rheumatic disease
\end{tabular}

NSAIDs Nonsteroidal anti-inflammatory drugs, ICU intensive care unit, $C C U$ cardiac care unit

require a DOAC or is at least several months after the index event, since the risk of recurrent VTE is highest during the first 3 months. For patients who require long-term anticoagulation or in whom the invasive procedure cannot be delayed, the next step is to determine whether procedurerelated bleeding risk is sufficiently high to warrant DOAC interruption. Some procedures, such as simple dental extractions, minor dermatologic procedures or cataract surgery, pose minimal bleed risk and do not require interruption of anticoagulation. Table 9 provides a list of procedures categorized by bleed risk. Table 10 lists additional characteristics that may predispose patients to bleeding.

When DOAC interruption is necessary, the cessation and resumption of the DOAC around the elective procedure is determined according to bleeding risk, renal function, and DOAC half-life $\left(\mathrm{t}_{1 / 2}\right)$ (Table 11). The half-life of a drug is the time for the blood plasma concentration of a substance to reach one-half of its steady-state value as a result of elimination processes. It requires five half-lives to eliminate $>95 \%$ of a therapeutic drug concentration. When pathways of elimination are diminished (e.g. renal impairment), it will require more time to clear the drug and the half-life will increase. Among hospitalized VTE patients who develop acute kidney injury (AKI), the DOAC $\mathrm{t}_{1 / 2}$ may become significantly prolonged.

For urgent or emergent procedures, determination of time of last ingestion and rapid assessment of residual anticoagulant effect should be performed with an appropriate assay if possible before proceeding with invasive interventions. In deciding whether an urgent/emergent procedure should be delayed until after an appropriate amount of time has elapsed since the last administration of the DOAC, the increased risk of bleeding should be weighed against the urgency of the procedure.

Once hemostasis is achieved, the DOAC should be resumed approximately $24 \mathrm{~h}$ post-operatively in low bleed risk situations, and this should be delayed to $48-72 \mathrm{~h}$ in high bleed risk patients (Tables 9, 10, and 11). VTE prophylaxis with UFH, LMWH or DOAC may be employed, if necessary, until therapeutic doses of DOAC are resumed. If the risk of bleeding precludes even prophylactic-dose anticoagulation from being given, mechanical VTE measures should be considered. In situations where a patient cannot tolerate oral therapy post-operatively, apixaban or rivaroxaban may be administered via NG or a parenteral agent may be utilized until the DOAC can be administered. In post-operative patients with ongoing epidural anesthesia, DOACs should be avoided. Guidelines regarding neuraxial anesthesia and anticoagulants set forth by the American Society of Regional Anesthesia and Pain Medicine (ASRA) [45] should be strictly followed to avoid spinal or epidural hematoma. Only anticoagulants endorsed by ASRA should be utilized while the epidural remains in place.

Several guidelines and reviews pertaining to perioperative management of anticoagulants have been published and form the basis for our guidance statements [41, 46, 47].

Guidance statement For VTE patients on DOAC therapy requiring TI for an invasive procedure, we suggest a carefully constructed, thoughtful approach that emphasizes communication between the provider managing the DOAC therapy, the clinician performing the procedure, and the patient and/or caregiver about the management of the DOAC. If TI is deemed necessary, we suggest that clinicians consider the patient's renal function, the DOAC $t_{1 / 2}$ and the associated bleeding risk when determining timing of cessation and resumption of the DOAC. We suggest avoiding routine use of bridge therapy during DOAC interruption.

5. How should patients with DOAC drug-drug interactions be managed?

Currently, the majority of available DOAC drug interaction data only illustrate changes in drug exposure conducted in pharmacokinetic studies of healthy volunteers. Available pharmacokinetic drug interaction data in actual patients are limited to subsets of the larger atrial fibrillation population clinical trials. It is unknown if these pharmacokinetic changes translate to pharmacodynamic effect resulting in excess bleeding or thrombotic events. 
Table 11 Cessation and resumption of DOAC for $\mathrm{TI}^{\mathrm{a}}[46,47,126,127]$

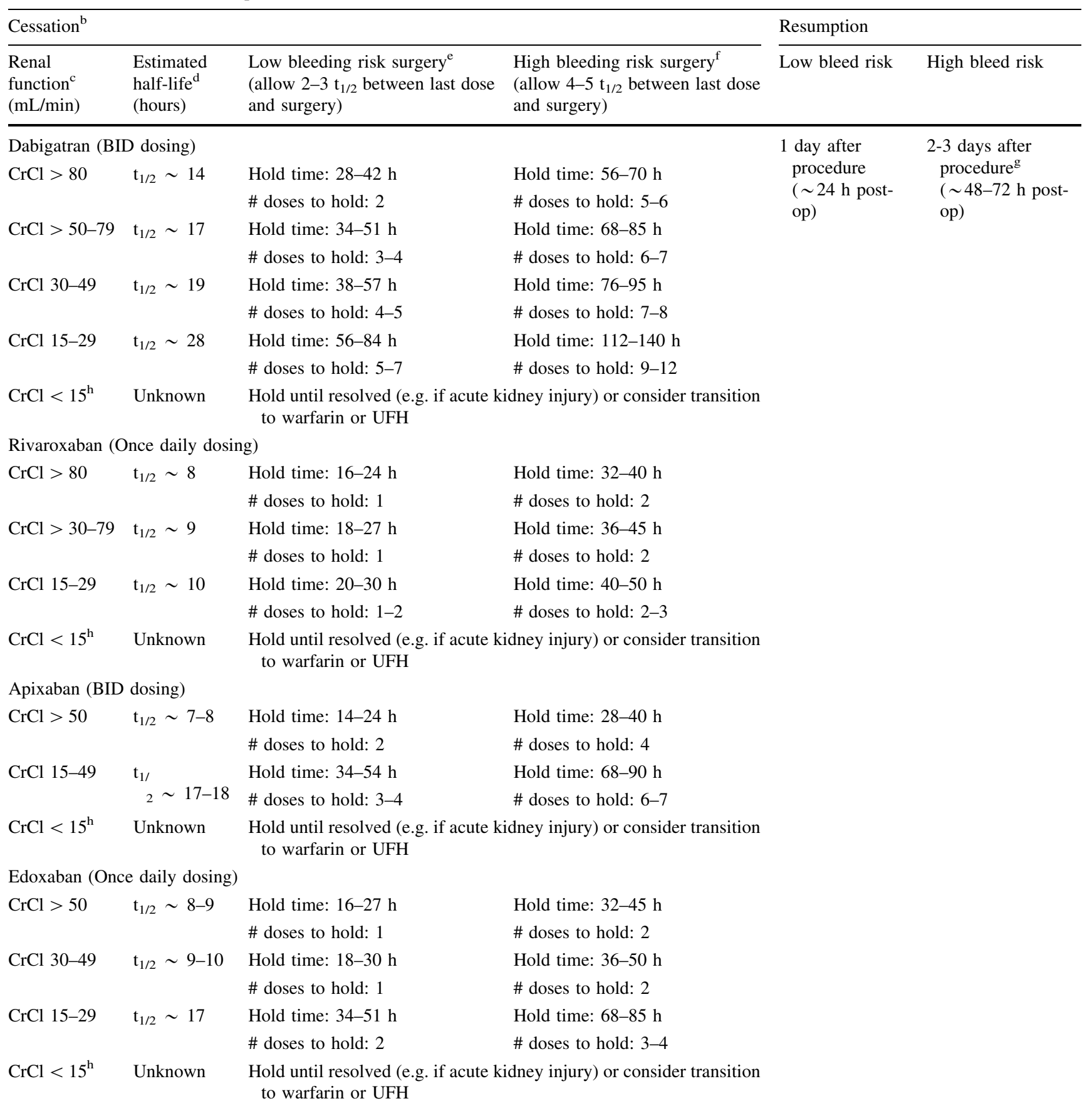

\footnotetext{
${ }^{a}$ Applies to both elective procedures and procedures among hospitalized patients on DOAC treatment

b Consider earlier cessation of DOAC for patients with additional bleed risk factors listed in Table 10

${ }^{c} \mathrm{CrCl}$ calculated using Cockroft-Gault method and actual body weight (ABW)

${ }^{d}$ Estimated $t_{1 / 2}$ based on renal clearance

e Aiming for mild to moderate residual anticoagulant effect at surgery (12-25\%)

${ }^{\mathrm{f}}$ Aiming for no or minimal residual anticoagulant effect (3-6\%) at surgery

$\mathrm{g}$ For patients at high risk for thromboembolism and bleeding after surgery, consider administering a prophylactic dose of anticoagulant on the first postoperative day. If the patient tolerates this, they may then be increased to treatment doses at $48-72 \mathrm{~h}$ post-procedure

${ }^{\mathrm{h}}$ Consider laboratory measurement with appropriate assay to determine when it is safe to proceed with surgery
} 
Fig. 2 P-gp effect on drug exposure. Reproduced with permission from Kaatz and Mahan [127]
Drug diffuses from intestinal lumen through luminal membrane into enterocyte. P-gp pumps drup out of cell back into intestinal lumen.

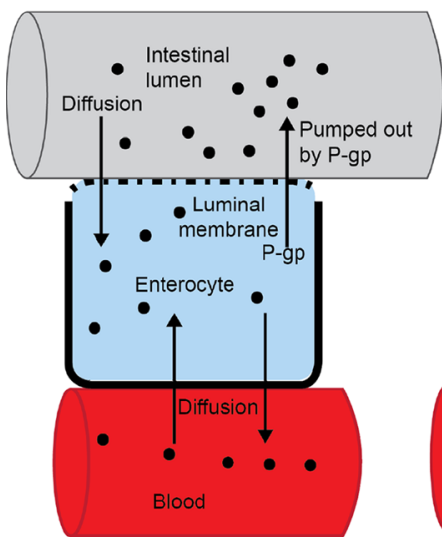

P-gp Inhibition

P-gp activity reduced; less drug pumped back into intestine, greater systemic exposure.

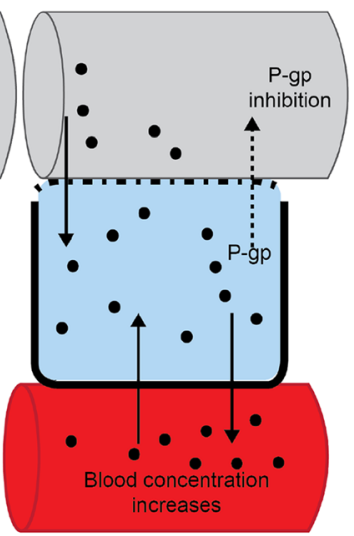

\section{P-gp Induction}

P-gp activity increased; more drug pumped back into intestine, less systemic exposure.

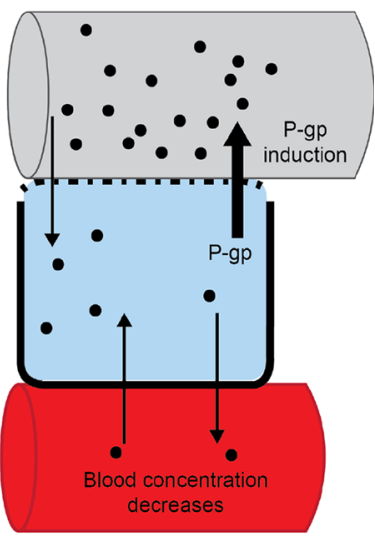

Table 12 Drug transport/metabolism/elimination characteristics of the direct oral anticoagulants $[11,12,15,16,48,49,128,129]$

\begin{tabular}{llll}
\hline & $\begin{array}{l}\text { P-gp } \\
\text { substrate }\end{array}$ & $\begin{array}{l}\text { CYP3A4 substrate }(\% \text { of } \\
\text { drug metabolized via } \\
\text { CYP3A4) }\end{array}$ & $\begin{array}{l}\text { \% renal } \\
\text { elimination }\end{array}$ \\
\hline Dabigatran & Yes & No & $\approx 80$ \\
Rivaroxaban & Yes & Yes $(\approx 33)^{\mathrm{a}}$ & $\approx 33$ \\
Apixaban & Yes & Yes $(\approx 25)^{\mathrm{b}}$ & $\approx 25$ \\
Edoxaban & Yes & No & $\approx 50$ \\
\hline
\end{tabular}

CYP3A4 Cytochrome 3A4, p-gp permeability-glycoprotein

${ }^{\text {a }}$ Total of $\approx 66 \%$ hepatic metabolism equally distributed between CYP3A4 and CYP2J2

b Total of $\approx 25 \%$ hepatic metabolism, mostly by CYP3A4, with minor contributions by CYP1A2, 2J2, 2C8, 2C9, and 2C19

Each of the DOACs is a substrate of permeability-glycoprotein (p-gp), an efflux transporter located in the membranes of the small intestine, blood-brain barrier, liver, and kidneys that regulates absorption of drugs into the bloodstream and tissues [48, 49] (Fig. 2). Hepatic enzyme Cytochrome 3A4 (CYP 3A4) metabolizes rivaroxaban and apixaban to varying degrees (33 and $25 \%$, respectively). Dabigatran is not a CYP3A4 substrate, and less than $4 \%$ of edoxaban is metabolized via CYP3A4 (Table 12). Drugs that induce (increase the function of) p-gp and/or CYP3A4 may decrease DOAC plasma concentrations and increase the risk for thromboembolic events, while drugs that inhibit (decrease the function of) p-gp and/or CYP3A4 may increase DOAC concentrations and increase bleeding risk.

Given that each of the DOACs has some proportion of renal elimination (dabigatran $80 \%$, rivaroxaban $33 \%$, apixaban $25 \%$, edoxaban $50 \%$ ) [49] (Table 12), patients with renal impairment or over age 75 years taking DOACs may be at a higher risk of bleeding complications [48, 5056], especially if they also have potential concomitant drug interactions (e.g. taking a p-gp and/or CYP3A4 inhibitor). It is important to note that these same patient characteristics (increasing age, impaired renal function and drug interactions) have been shown to convey an increased bleeding risk with warfarin as well [57].

In VTE treatment trials, dyspepsia and gastrointestinal (GI) bleeding were more common in patients taking dabigatran as compared to warfarin or placebo [6,7]. Patients with these adverse effects may be frequently prescribed proton-pump inhibitors (PPIs). Even though dabigatran requires an acidic gastric environment for absorption [58], pharmacokinetic studies have not shown a clinically significant reduction in dabigatran exposure with concomitant PPI $[14,59]$. Therefore, PPIs may be safely co-administered with dabigatran without need for dose adjustment. Tables 13 and 14 provide an evidence-based summary of drug interactions with dabigatran and the anti-Xa inhibitors. Additionally, the product labeling for each of the DOACs contains detailed dosing information and necessary adjustments that consider route of metabolism and elimination and degree of renal impairment.

Antiplatelet agents and non-steroidal anti-inflammatory drugs (NSAIDs)

When each of the DOACs were studied in combination with dual antiplatelet therapy (aspirin and clopidogrel) for acute coronary syndromes, investigators observed a 
Table 13 Permeability glycoprotein (p-gp) drug-drug interactions with dabigatran and edoxaban [16, 48, 59, 130-135] (list is not exhaustive)

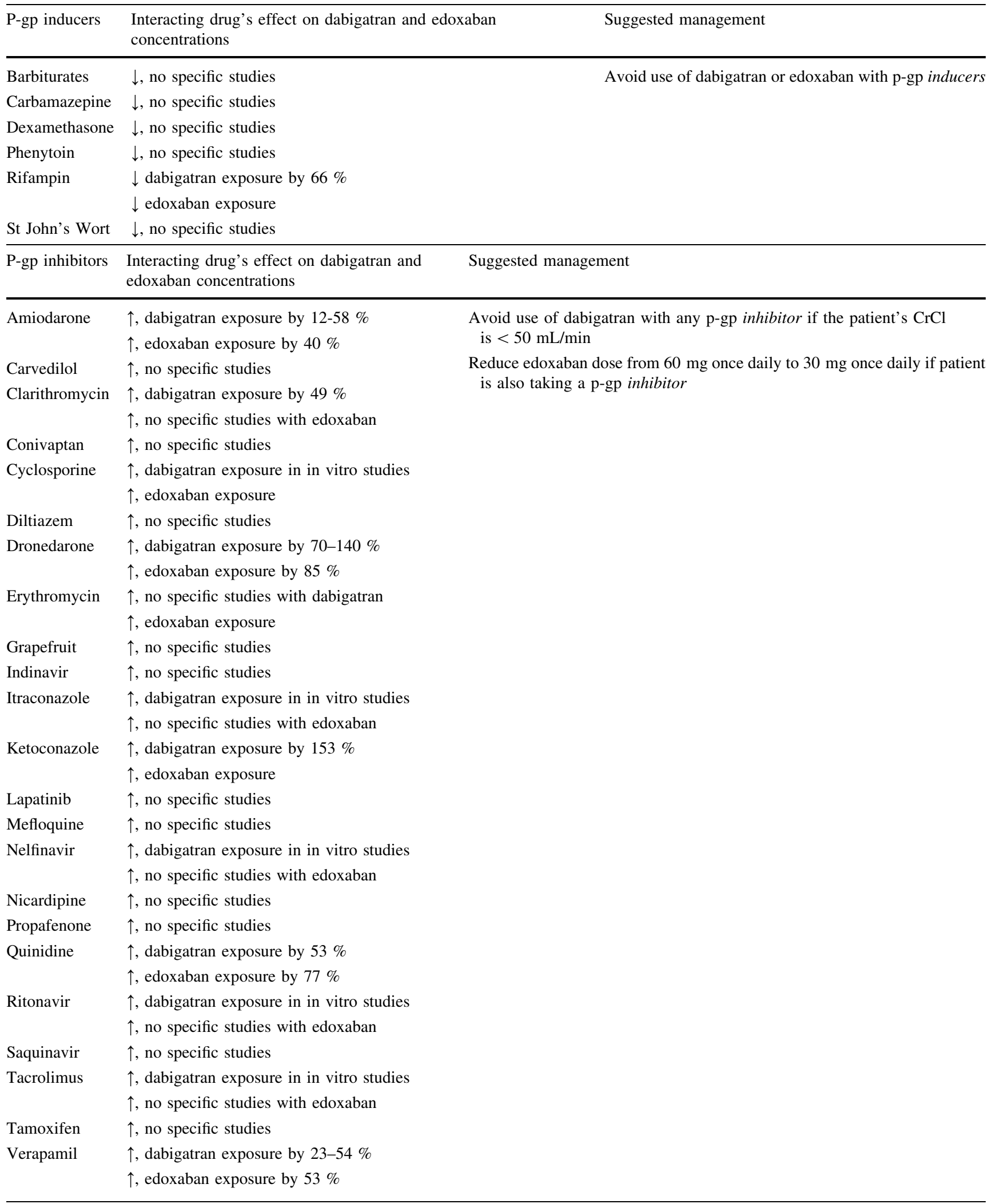

$\mathrm{CrCl}$ Creatinine clearance, $\mathrm{p}-\mathrm{gp}$ permeability glycoprotein 
Table 14 Permeability glycoprotein (p-gp) and Cytochrome 3A4 drug-drug Interactions with rivaroxaban and apixaban) [134-139] (list is not exhaustive)

\begin{tabular}{|c|c|c|}
\hline $\begin{array}{l}\text { P-gp and strong CYP3A4 } \\
\text { inducers }\end{array}$ & $\begin{array}{l}\text { Interacting drug's effect on rivaroxaban/apixaban } \\
\text { concentration }\end{array}$ & Suggested management \\
\hline Barbiturate & $\downarrow$, no specific studies & \multirow{5}{*}{$\begin{array}{l}\text { Avoid use of rivaroxaban or apixaban with p-gp and strong } \\
\text { CYP3A4 inducers }\end{array}$} \\
\hline Carbamazepine & $\downarrow$, no specific studies & \\
\hline Phenytoin & $\downarrow$, no specific studies & \\
\hline Rifampin & $\downarrow$, rivaroxaban and apixaban exposure by & \\
\hline St John's Wort & $\downarrow$, no specific studies & \\
\hline $\begin{array}{l}\text { P-gp and strong } \\
\text { CYP3A4 inhibitors }\end{array}$ & $\begin{array}{l}\text { Interacting drug's effect on Factor Xa } \\
\text { inhibitor concentration }\end{array}$ & Suggested management \\
\hline Clarithromycin & $\begin{array}{l}\uparrow, \text { rivaroxaban exposure by } 54 \% \uparrow, \text { no } \\
\text { specific studies for apixaban }\end{array}$ & \multirow{6}{*}{$\begin{array}{l}\text { Rivaroxaban: } \\
\text { Avoid use of rivaroxaban with p-gp and strong CYP3A4 inhibitors } \\
\text { Apixaban: } \\
\text { If taking } 5 \mathrm{mg} \text { or } 10 \mathrm{mg} \text { BID reduce dose by } 50 \% \text { if combined with } \\
\text { strong p-gp and CYP3A4 inhibitors } \\
\text { If taking } 2.5 \mathrm{mg} \text { BID avoid apixaban with strong p-gp and CYP3A4 } \\
\text { inhibitors }\end{array}$} \\
\hline Conivaptan & $\uparrow$, no specific studies & \\
\hline Grapefruit & \multirow{2}{*}{$\begin{array}{l}\uparrow, \text { no specific studies } \\
\uparrow, \text { no specific studies }\end{array}$} & \\
\hline Indinavir & & \\
\hline Itraconazole & $\uparrow$, no specific studies & \\
\hline Ketoconazole & $\begin{array}{l}\uparrow \text {, rivaroxaban exposure by } 160 \% \\
\uparrow \text {, apixaban exposure by } 200 \%\end{array}$ & \\
\hline Nelfinavir & $\uparrow$, no specific studies & \\
\hline Posaconazole & $\uparrow$, no specific studies & \\
\hline Ritonavir & $\begin{array}{l}\uparrow \text {, rivaroxaban exposure by } 160 \% \\
\uparrow, \text { no specific studies for apixaban }\end{array}$ & \\
\hline Saquinavir & $\uparrow$, no specific studies & \\
\hline $\begin{array}{l}\text { P-gp and moderate } \\
\text { CYP3A4 inhibitors }\end{array}$ & $\begin{array}{l}\text { Interacting drug's effect on rivaroxaban/ } \\
\text { apixaban concentration }\end{array}$ & Suggested management \\
\hline Cyclosporine & $\uparrow$, no specific studies & Rivaroxaban: \\
\hline Diltiazem & $\begin{array}{l}\uparrow \text {, apixaban exposure by } 30-40 \% \\
\uparrow, \text { no specific studies with rivaroxaban }\end{array}$ & $\begin{array}{l}\text { Avoid use of rivaroxaban with p-gp and moderate CYP3A4 } \\
\text { inhibitors if } \mathrm{CrCl} \text { is }<80 \mathrm{~mL} / \mathrm{min}\end{array}$ \\
\hline Dronedarone & $\uparrow$, no specific studies & Apixaban: \\
\hline Tamoxifen & $\uparrow$, no specific studies & \multirow{2}{*}{$\begin{array}{l}\text { No dose adjustment is recommended with } \mathrm{p} \text {-gp and moderate } \\
\text { CYP3A4 inhibitors. Use with caution }\end{array}$} \\
\hline Verapamil & $\uparrow$, no specific studies & \\
\hline
\end{tabular}

$\mathrm{CrCl}$ Creatinine clearance, $\mathrm{CYP} 3 \mathrm{~A} 4$ cytochrome $3 \mathrm{~A} 4, p$-gp permeability lycoprotein

clinically significant increase in major bleeding in patients taking triple therapy [60-62]. The DOAC VTE treatment trials permitted low-dose concomitant aspirin, and dual antiplatelet therapy was permitted in the dabigatran and rivaroxaban trials. The rate of low-dose aspirin use in the study populations for dabigatran, rivaroxaban, and apixaban ranged from 8 to $14 \%$ and was not reported in the edoxaban trial $[4,5,7-10,63]$. In a sub-analysis of the rivaroxaban VTE treatment trial, patients taking rivaroxaban and low-dose aspirin had a significantly higher risk of clinically relevant bleeding (hazard ratio (HR) 1.81, $95 \%$ CI 1.36-2.41) and a non-significant increase in major bleeding (HR 1.50, $95 \%$ CI 0.63-3.61) compared to rivaroxaban-only patients [63].
Each of the VTE treatment trials allowed concomitant NSAID use (the edoxaban trial restricted NSAID use to $<4$ days per week [4, 5, 7-10], with $43 \%$ of dabigatran patients and $23 \%$ of rivaroxaban patients reporting concomitant NSAID use) $[7,60]$. Patients taking rivaroxaban and NSAIDs had a 2.5-fold higher rate of major bleeding (HR 2.56, $95 \%$ CI 1.21-5.39) and a 2-fold higher rate of clinically relevant bleeding (HR 1.9, $95 \%$ CI 1.45-2.49) compared to those not taking NSAIDs. In this study, $14 \%$ of the clinically relevant bleeding events were gastrointestinal [63].

Potential drug interactions should be assessed to determine if an alternative non-interacting medication is available to treat the patient's condition. The duration of 
interaction exposure should be evaluated, as well as the patient's risk for a recurrent VTE or major bleeding. Patients at high risk of recurrent VTE (VTE event in the last 3 months or with ongoing VTE risk factors) or at a high risk of bleeding may be particularly vulnerable to DOAC drug interactions. Conversely, patients at a lower risk of recurrent VTE or bleeding may be able to tolerate a moderate drug-drug interaction combination without substantially increasing their risk of adverse events. As always, it is imperative to educate and involve the patient in the discussion. If there is no clear guidance from the literature regarding a specific drug interaction, explain this to the patient and the potential risks involved of each possible approach to management, including alternate therapy. Regular follow-up is advised to assess for adverse events.

Guidance statement DOAC drug-drug interaction management must be patient-specific and incorporate multiple clinical parameters, such as concomitant renal impairment, extremes of body weight or advanced age. We suggest that clinicians avoid concomitant use of dabigatran and edoxaban with a strong inducer or inhibitor of p-gp and avoid use of rivaroxaban and apixaban with combined strong inducers and inhibitors of p-gp and CYP3A4.

For patients requiring concomitant DOAC therapy with a p-gp and/or CYP3A4 inhibitor, we suggest clinicians closely follow the detailed dose adjustments or avoidance provided in the product labeling. We suggest concomitant antiplatelet or NSAIDs be avoided during DOAC therapy unless the potential benefit clearly justifies the increased bleeding risk.

6. How should patients transition between anticoagulants?

In general, the need to switch between agents exposes the patient to periods of increased thromboembolic and bleeding risks. In the ROCKET AF [64] and ARISTOTLE trials [65] of rivaroxaban and apixaban, respectively, a 4-fold increase risk of stroke or bleeding was seen at the end of the study period, attributable to lack of a structured approach to ensuring study patients did not have a "gap" in therapeutic levels of anticoagulation while transitioning to warfarin [66]. This underscores the importance of having a carefully constructed and thoughtful approach for anticoagulant transitions, especially for transition to warfarin.

A recent study from a large outpatient anticoagulation clinic showed approximately $4-6 \%$ of their warfarin patients are being switched to a DOAC annually [67]. A Danish study among atrial fibrillation patients found that the majority $(51.2 \%)$ of patients prescribed a DOAC had switched to a VKA within 6 months. Reasons for the high rate of switching in this study are not known. However, these two studies collectively suggest that switches between anticoagulants are not infrequent and may be expected to increase [68].

There are a variety of reasons patients may switch between anticoagulants [66]. Patients may require a switch from parenteral anticoagulants to DOAC for longer-term outpatient management. Patients may also be switched from warfarin to a DOAC, or DOAC to DOAC, if they experience a therapeutic failure, have drug intolerance (e.g. rash, dyspepsia, etc.) or if they express a preference for DOAC therapy and are deemed to be an appropriate candidate based on criteria previously discussed [66].

In addition, there may be times when a patient needs to be switched from a DOAC to warfarin, for many of the same reasons, such as drug intolerance, failure or preference. Patients may also acquire a new condition or comorbidity that is a contraindication to DOAC therapy, such as pregnancy, severe renal impairment, placement of a mechanical valve or need for dual antiplatelet therapy that necessitates a switch [66].

Other situations that might warrant a switch include gastric bypass surgery where gastric absorption may be significantly altered or the need for new medication, such as protease inhibitor, that poses a major drug interaction with a DOAC. In these instances it may be best to maintain the patient on warfarin therapy so levels of anticoagulation can be readily monitored. Patients may also not be able to tolerate oral medications during the perioperative period (e.g. bowel resection or NPO status) and thus may need to be transitioned from a parenteral back to a DOAC or from prophylactic-dose DOAC to treatment-dose DOAC [66].

If a VTE patient requires a switch between anticoagulants, clinicians should employ a carefully constructed approach that takes into consideration the patient's anticoagulation status at the time of the switch, their renal function and the pharmacokinetics of the individual DOAC to avoid significant under- or over anticoagulation of their patient.

Tables 15 and 16 provide information regarding appropriate switching strategies for heparin, LMWH and the DOACs.

Guidance statement Switching from warfarin to a DOAC:

When switching from warfarin to dabigatran, apixaban, rivaroxaban or edoxaban, discontinue warfarin and start the DOAC when the International Normalized Ratio (INR) has decreased to $<2$ for dabigatran and apixaban $(<3$ for rivaroxaban, $<2.5$ for edoxaban) to avoid periods of inadequate or excessive anticoagulation. In cases where the target INR was 2.5-3.5 or higher due to recurrent VTE, initiate the DOAC when the INR is near 2.5 or the lower end of the specified range. 
Switching from non-warfarin anticoagulant to a DOAC: When switching from a DOAC to a different DOAC or from $L M W H /$ fondaparinux to a DOAC, start the new $\overline{D O A} \mathrm{C} 0-2 \mathrm{~h}$ prior to the next scheduled administration of the original anticoagulant and then discontinue the original anticoagulant.

When switching from IV UFH to a DOAC, stop the heparin infusion and begin administration of the DOAC at the time of UFH discontinuation.

When switching from SC UFH treatment to a DOAC, stop the SC UFH and initiate the DOAC approximately 4-5 $h$ after the last dose of SC UFH.

For additional information regarding switching from a DOAC to warfarin or a non-warfarin anticoagulant, readers are also referred to the respective chapters within this compendium by Wittkowsky and Witt.

7. How should DOAC-associated bleeding be managed?

In both VTE treatment trials and atrial fibrillation trials, rates of major bleeding were shown to be comparable or lower with DOACs than with conventional approaches using LMWH and warfarin [3-10, 64, 65, 69, 70]. There is encouraging evidence to suggest that DOAC patients who develop a major bleed require less blood or factor products, have shorter lengths of hospital stay and potentially have better outcomes compared to patients experiencing VKAassociated major hemorrhage [71-73]. Despite early concerns regarding excessive bleeding with dabigatran, postmarketing surveillance data from the FDA supports a favorable risk-benefit profile [74].

Nevertheless, DOAC-treated patients may experience a hemorrhagic episode and require intervention (Fig. 3). Hospitals should develop evidence-based antithrombotic bleeding and reversal protocols that contain clinical decision support for providers and are easy to access and use in high-stress urgent or emergent situations. The general approach to a bleeding patient, regardless of anticoagulant, includes withholding the anticoagulant, hemodynamic monitoring, resuscitation with fluid and blood products, mechanical compression if possible, and definitive procedural intervention to identify and treat the source of bleed if indicated. In addition to supporting blood pressure, assertive fluid resuscitation will promote renal elimination of DOACs, particularly dabigatran. If DOAC ingestion within the last $6 \mathrm{~h}$ can be confirmed, clinicians may consider use of oral activated charcoal for any of the DOACs. In addition to determining time of last DOAC ingestion, clinicians should also rapidly evaluate the patient's renal function to estimate remaining duration of drug exposure, and potential need for additional interventions, such as hemodialysis. Hemodialysis may be considered for dabigatran patients, particularly if they have impaired renal function and will have prolonged exposure to dabigatran without the aid of extracorporeal removal. Hemodialysis is not an effective option for removal of direct Xa inhibitors due to their extensive protein binding.

If a patient is refractory to general approaches, clinicians may consider non-specific reversal strategies. Several studies of clotting factor concentrates, such as activated and non-activated prothrombin complex concentrates (PCCs) or recombinant Factor VIIa, for DOAC reversal have been reported. This evidence, recently summarized in a systematic review, is of very low quality, as it is limited to in vitro studies, animal models or studies in healthy human volunteers and often shows conflicting results [75]. Additionally, most of these studies evaluated surrogate outcomes, such as normalization of global coagulation assays, instead of relevant clinical outcomes of in vivo hemostasis and mortality. Overall, results suggest that either inactive 4-Factor PCC $\left(\mathrm{KCentra}^{\circledR}\right) 50 \mathrm{U} / \mathrm{kg}$ or active PCC (aPCC, FEIBA $\left.{ }^{\circledR}\right) 80 \mathrm{U} / \mathrm{kg}$ are reasonable options for reversal of direct $\mathrm{Xa}$ inhibitors and direct thrombin inhibitors, respectively [76-85]. These agents contain procoagulant factors II, VII, IX and X. Activated PCC may pose a greater risk of thrombosis, but may be considered if inactive 4-Factor PCC is not available. Recombinant Factor VIIa is not recommended as a first-line reversal agent. Unlike the PCCs, rFVIIa is not formulated with marginal amounts of anticoagulants (e.g. Protein C, Protein S, Antithrombin, heparin) to mitigate thrombotic risk. Metaanalyses suggest that use of rFVIIa results in higher rates of

Table 15 Switching to DOACs

\begin{tabular}{|c|c|}
\hline \multicolumn{2}{|c|}{ Warfarin to DOAC } \\
\hline Dabigatran $^{\mathrm{a}}$ & Start when INR $<2.0$ \\
\hline Rivaroxaban $^{\mathrm{a}}$ & Start when INR $<3.0$ \\
\hline Apixaban $^{\mathrm{a}}$ & Start when INR $<2.0$ \\
\hline Edoxaban $^{\mathrm{a}}$ & Start when INR $\leq 2.5$ \\
\hline \multicolumn{2}{|c|}{ LMWH to DOAC } \\
\hline \multicolumn{2}{|l|}{ Dabigatran } \\
\hline Rivaroxaban & Start DOAC within $0-2 \mathrm{~h}$ of the time of next \\
\hline Apixaban & scheduled dose of LMWH \\
\hline Edoxaban & \\
\hline \multicolumn{2}{|c|}{ (iv) UFH to DOAC } \\
\hline \multicolumn{2}{|l|}{ Dabigatran $^{\mathrm{a}}$} \\
\hline Rivaroxaban $^{\mathrm{a}}$ & Start DOAC immediately after stopping iv UFH \\
\hline \multicolumn{2}{|l|}{ Apixaban $^{\mathrm{a}}$} \\
\hline Edoxaban $^{\mathrm{a}}$ & Start edoxaban $4 \mathrm{~h}$ after stopping iv UFH \\
\hline
\end{tabular}

As a general rule, we suggest that as INR drops below 2.5, a DOAC can be started

As a general rule, we suggest that each DOAC can be started within $30 \mathrm{~min}$ after stopping (iv) UFH

a Recommendations adapted from company's package insert 
Table 16 Switching to warfarin

\begin{tabular}{ll}
\hline DOAC to warfarin \\
Dabigatran $^{\mathrm{a}}$ & Start warfarin and overlap with dabigatran; \\
& $\mathrm{CrCl} \geq 50 \mathrm{~mL} / \mathrm{min}$, overlap 3 days \\
& $\mathrm{CrCl} 30-50 \mathrm{~mL} / \mathrm{min}$, overlap 2 days \\
& $\mathrm{CrCl} 15-30 \mathrm{~mL} / \mathrm{min}$, overlap 1 day \\
Rivaroxaban $^{\mathrm{a}}$ & Stop DOAC; start warfarin and LMWH at time of \\
Apixaban $^{\mathrm{a}}$ & next scheduled DOAC dose and bridge until \\
& INR $\geq 2.0$ \\
Edoxaban $^{\mathrm{a}}$ & For $60 \mathrm{mg}$ dose, reduce dose to $30 \mathrm{mg}$ and start \\
& warfarin concomitantly \\
& For $30 \mathrm{mg}$ dose reduce dose to $15 \mathrm{mg}$ and start \\
& warfarin concomitantly \\
& Stop edoxaban when INR $\geq 2.0$
\end{tabular}

Overlap intended to avoid under-anticoagulation while warfarin effect developing. When DOAC overlapped with warfarin, measure INR just before next DOAC dose since DOAC can influence INR

As a general rule, we believe either approach (i.e. stop DOAC then start LMWH and warfarin; or overlap warfarin with DOAC, measure INR just before next DOAC dose and stop DOAC when INR $\geq 2.0$ ) can be used for all DOAC to warfarin transitions

$\mathrm{CrCl}$ creatinine clearance

a Recommendations adapted from company's package insert

thrombosis than PCCs [86, 87]. Additionally, because both inactive and active PCCs already contain FVII, there is no rationale to employ rFVIIa as a first-line agent for DOAC reversal. Therefore, we suggest rFVIIa only be used in event PCCs have failed to restore hemostasis in a patient with life-threatening bleeding. Clinicians should carefully weigh risk versus benefit of factor concentrate administration as there is no evidence that these agents improve outcomes and the risk of thrombosis is quite significant [86, 87]. Given the low quality of evidence, it is not unreasonable to withhold these strategies, particularly if there is significant underlying thromboembolic risk.

Fresh frozen plasma should not be used for DOAC reversal, as the volume that would be required to overwhelm the inhibition of thrombin or Factor Xa precludes use in urgent or emergent situations and would likely lead to adverse events, such as fluid overload. Desmospressin or platelet transfusion may be considered in DOAC patients recently on concomitant antiplatelet therapy. Antifibrinolytics agents (tranexamic acid, aminocaproic acid) may be considered as adjunctive therapies if the patient is failing to respond.

Until more robust data or specific antidotes are available, clinicians are limited to existing approaches that have been summarized in several recent reviews [75, 88-90].

Several clinical trials of specific antidotes for both DTIs and $\mathrm{Xa}$ inhibitors have been completed or are underway [91-104]. Phase II studies and preliminary data from Phase III studies show these agents to be safe and effective in providing complete and sustained DOAC reversal. They have received expedited review from the FDA and are expected to be commercially available within the next few years.

Guidance statement We suggest hospitals develop evidence-based antithrombotic reversal and bleeding protocols that contain clinical decision support for providers and are easy to access and use in urgent or emergent situations. We suggest that general approaches to bleed management be employed for all patients presenting with severe hemorrhage. For DOAC patients, clinicians should attempt to rapidly determine time of last DOAC ingestion and patient's renal function to estimate remaining duration of exposure and potential utility of additional interventions. Until specific antidotes are available, we suggest clinicians consider use of non-specific reversal strategies in patient's refractory to standard therapies. For direct Xa inhibitors, non-activated 4-Factor PCC $50 \mathrm{U} / \mathrm{kg}$ may be considered. For direct thrombin inhibitors, either 4-Factor non-activated PCC $50 \mathrm{U} / \mathrm{kg}$ or activated PCC $80 \mathrm{U} / \mathrm{kg}$ may be considered. However, it is reasonable to withhold these strategies given the associated thrombosis risk and the low quality of evidence that they are beneficial in this setting.

8. What is an appropriate care transitions and follow-up strategy for VTE patients on DOAC therapy?

Inadequate care transitions have been implicated in an estimated annual \$25-45 billion in wasted healthcare dollars in the US [105]. Thus, the importance of care transitions has been brought to forefront through numerous national quality initiatives that have emerged in recent years. When looking at approaches specific to anticoagulation patients, implementation of pharmacy-directed anticoagulation services (PDAS) has been shown to significantly improve adherence with specified care transition metrics as well as clinical outcomes [106]. Also, PDAS have been shown to improve patient satisfaction with their care, which now has a direct impact on Medicare reimbursement to hospitals [107]. In efforts to further systematize the delivery of anticoagulation care, reduce adverse drug events and improve care transitions in this high-risk population, a recent consensus statement from EHR Task Force of the New York State Anticoagulation Coalition has called for the incorporation of key anticoagulation-related features into existing EHRs or specialized anticoagulation management systems [108].

There are important nuances in the management of DOACs for VTE, and some of these are not well known. Each of the DOACs requires a dose de-escalation or switch from parenteral therapy at a specified time. The importance of this was recently highlighted in an ISMP alert (https:// www.ismp.org/newsletters/acutecare/issue.aspx?id=82) in which a patient prescribed rivaroxaban was given both the 


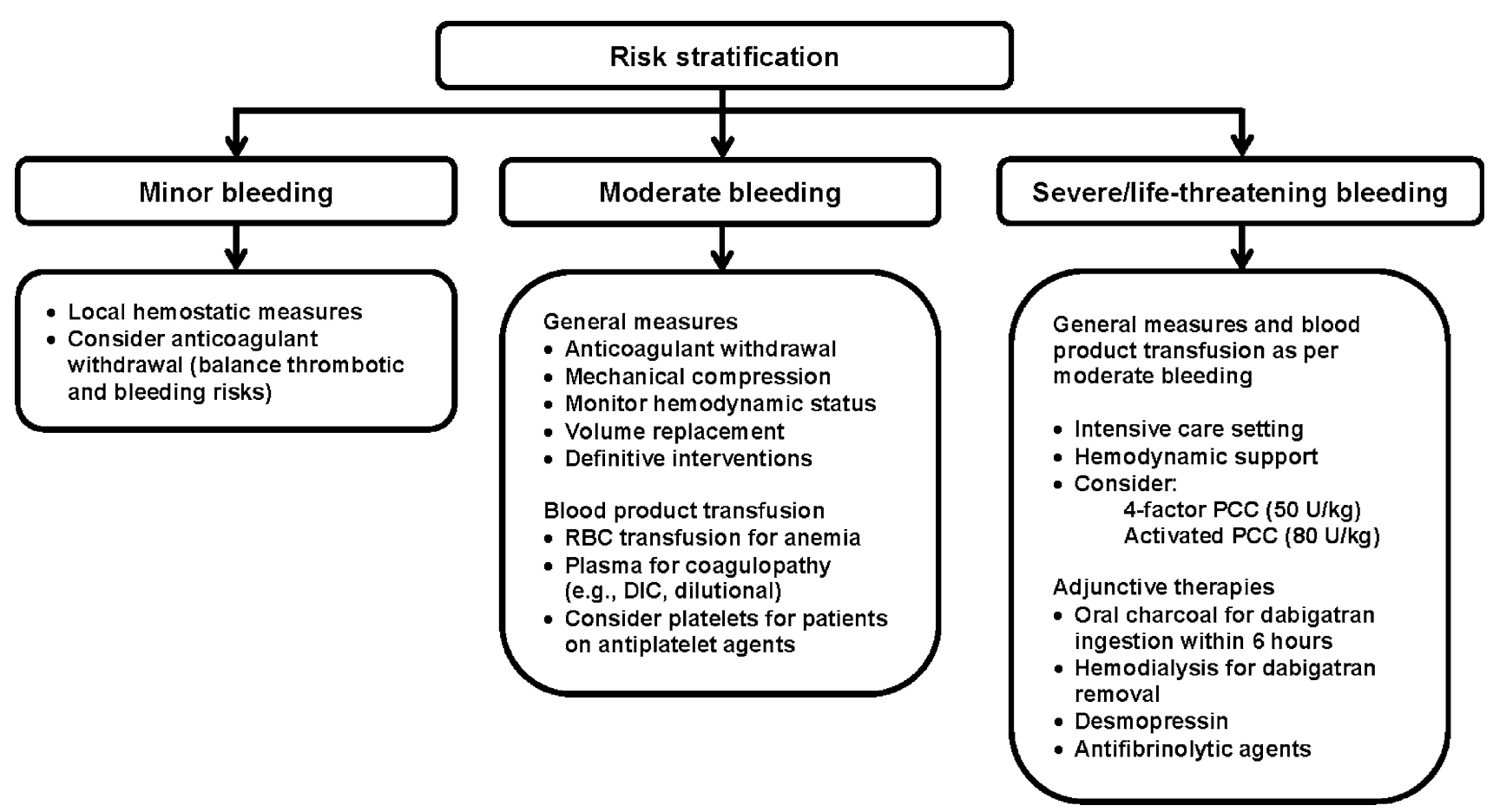

Fig. 3 Management of DOAC-associated bleeding

$15 \mathrm{mg}$ BID and $20 \mathrm{mg}$ once daily prescriptions prior to discharge. The patient erroneously took both the $15 \mathrm{mg}$ tablets and the $20 \mathrm{mg}$ tablets for several days before the error was discovered. This underscores the importance of clinician familiarity with dosing strategies combined with strong infrastructures, educational processes and thorough handoffs that support accurate and timely implementation of these changes to avoid adverse events [109, 110].

Similar to conventional therapies for VTE treatment, clinicians should evaluate patient eligibility for outpatient or early discharge DOAC therapy, as this has been shown to be safe and effective and provides significant cost savings to the healthcare system [111]. The advent of LMWH and fondaparinux significantly enhanced the feasibility of outpatient treatment during transition to warfarin. Outpatient VTE treatment is made even more feasible with the availability of the DOACs. As with conventional therapies, DOAC patients must meet certain clinical, behavioral and social criteria to be considered a viable candidate for outpatient therapy [111]. For stable patients with acute DVT that does not warrant thrombolysis or thrombectomy, outpatient therapy is an option as long as they are deemed likely to be adherent with medications and follow up, have confirmed ability to obtain the anticoagulant(s), have expressed understanding of their condition and what to do in the event of bleeding or clotting, and have a good social support system at home. Clinicians tend to be less comfortable treating patients with a pulmonary embolism in the outpatient setting. However, evidence for this strategy in appropriately selected patients is increasing. There are clinical prediction tools, such as the modified Pulmonary Embolism Severity Index (PESI) score [112] that aid in identifying PE patients with a low risk of adverse outcomes that may be considered for outpatient treatment (Table 17).

Care transitions can also occur within the hospital, such as when patients transfer to or from the ICU. At each transition, a review of the patient's medication profile and communication of therapeutic plans for each patient issue should be affected between the previous and current multidisciplinary teams. Surgical patients on DOACs warrant particular attention during care transitions within the hospital, as clinicians have far more experience with managing temporary interruptions in warfarin therapy, and staff may not be familiar with management of DOACs in the perioperative period, or even recognize DOACs as anticoagulants. Thus, potential transitions between drug therapies and across care settings (e.g. medical ward to OR and back) require thoughtful consideration and planning.

While DOACs do not require routine outpatient monitoring and adjustment, a standardized follow-up strategy needs to be delineated to facilitate periodic patient evaluation for clinically relevant issues $[110,113]$.

Guidance statement We suggest that hospitals implement systematic DOAC management and documentation processes that address appropriate patient selection, dose initiation, 
perioperative management, switches between anticoagulants and transitions between care settings. Whenever possible, implementation of a specialized inpatient and outpatient anticoagulation services is strongly encouraged. We also strongly recommend that clinicians utilize a DOAC discharge checklist (Table 18) to ensure all key aspects of patient care and DOAC therapy are addressed.

9. How can patients enhance safety and efficacy of their DOAC therapy?

Studies have shown that patients who are actively engaged in their healthcare experience have better care experiences, improved outcomes and lower overall healthcare costs $[114,115]$. One method to "activate" patients and caregivers is to increase their health literacy via education about their disease state and medication therapies. DOAC education for patients and caregivers should be individualized, drug specific and provided in the patient's preferred language at an appropriate literacy level. As the number of indications and evidence for DOACs expands, educational tools can quickly become outdated. It is important to involve anticoagulation resources, such as a PDAS, in regularly updating DOAC educational materials or obtaining them from contemporary, reliable sources (Tables 19, 20, and 21).

It is recommended to employ multiple modalities of education, such as verbal, written and video to reinforce key points as this will help achieve better outcomes [116]. Unfortunately, this is not always done. According to a survey conducted by the ISMP [117], 1 in 4 nurses indicate they do not provide written information to accompany verbal information provided to patients about their medications. Common reasons cited included no written materials being available, written materials not available in languages other than English, or written materials not appropriate for patients with poor literacy skills. Written materials should be developed to provide helpful reinforcement and reminders of safety issues.

Understanding how patients prefer to learn, type of media they value most and determining in advance how visual or hearing impairments may impact the educational process will help determine the best educational approach.

As education is provided, confirmation of a patient's comprehension of their disease and care plan is key. The teachback method (can the patient/caregiver accurately explain the information back to the educating clinician using their own words?) is a widely accepted means of assessing comprehension and should be integrated into all DOAC educational efforts. Including family members, caregivers or significant others in the education process may improve patient care and outcomes.

Table 5 summarizes key characteristics specific to each DOAC that are relevant to optimal use of these agents.
Table 17 Simplified PESI (Pulmonary Embolism Severity Index) score [112]

Predicts 30-day outcomes of patients with PE

\begin{tabular}{ll}
\hline Variable & Score \\
\hline Age $>80$ years & 1 \\
History of cancer & 1 \\
History of chronic cardiopulmonary disease & 1 \\
Systolic blood pressure $<100 \mathrm{~mm} \mathrm{Hg}$ & 1 \\
Heart rate $>110$ & 1 \\
$\mathrm{O}_{2}$ saturation $<90 \%$ & 1 \\
\hline
\end{tabular}

Score of $0=$ low risk (consider outpatient therapy)

Score $>0=$ high risk

Table 18 DOAC discharge checklist for optimal care transitions

Patient is an appropriate DOAC candidate

Assess patient's eligibility for outpatient treatment

Consistent access to DOAC (affordability, retail availability)

If transitioning to rehabilitation or skilled nursing facility, ensure DOAC on formulary

DOAC identified and understood as an oral anticoagulant by patient, caregivers and providers

Provision of thorough DOAC education to patient and/or caregiver in their preferred language and at an appropriate literacy level

Safety net phone number provided to patient/caregiver (Who to call with questions)

Referral or handoff to appropriate provider (anticoagulation clinic, PCP, etc.)

Time of last drug administration in current setting and time of next scheduled dose in new setting

Prescribed strategy for appropriate dose change after initial therapy (either switch to DOAC or DOAC dose de-escalation)

Consolidated documentation and communication to next care setting of key information such as

Indication for anticoagulation

Intended duration of therapy

DOAC dose and scheduled time of administration

Contact information for anticoagulation provider

Follow-up arranged for periodic (every 3-12 months) assessment of the following

Renal function

Liver function

Upcoming invasive procedures

New drug interactions

New contraindications

$D O A C$ direct-acting oral anticoagulant, $P C P$ primary care physician

These characteristics should be incorporated into comprehensive DOAC patient education processes and should be considered prior to prescribing.

Patients and caregivers are also more actively engaged when their values and preferences are considered. 
Table 19 Patient education resources

Web-based patient and family educational resources

Patient Guides published by manufacturer (accompanies Product Insert)

\section{www.pradaxa.com \\ www.xarelto-us.com \\ www.eliquis.com \\ http://www.savaysa.com \\ Patient booklet}

Your guide to preventing and treating blood clots http://www.ahrq.gov/patientsconsumers/prevention/disease/bloodclots.html

Patient education video

Blood thinner pills: your guide to using them safely http://www.ahrq.gov/patientsconsumers/diagnosis-treatment/treatments/btpills/btpills.html

Anticoagulation forum-Centers of Excellence Resource Center/Patient and Family Education Pillar

Table 20 Drug-specific educational points for DOACs and VTE treatment $[11,12,15,16]$

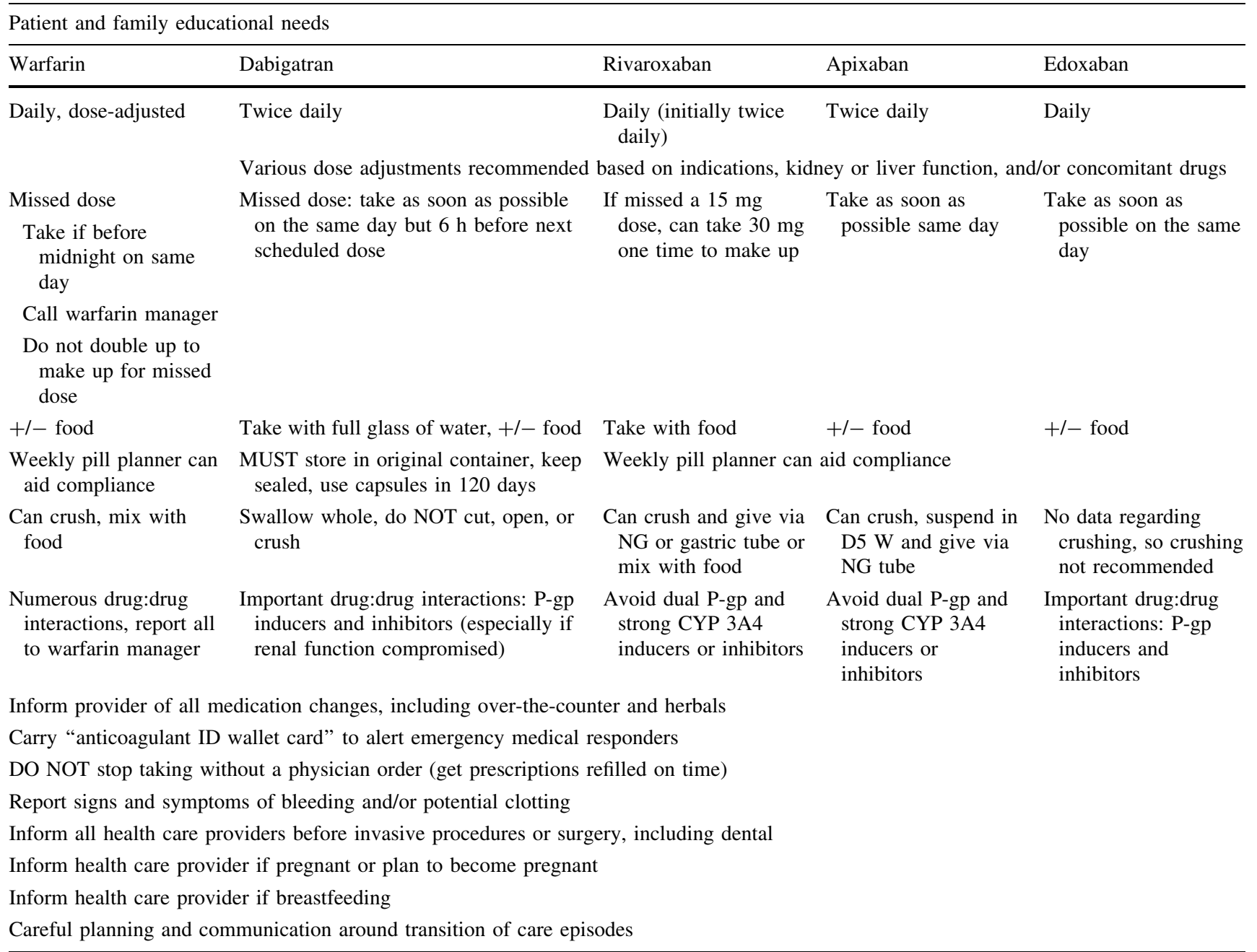

$D O A C$ direct oral anticoagulant, $V T E$ venous thromboembolism, $N G$ nasogastric 
Table 21 Patient education and safety tips to optimize DOAC use

\begin{tabular}{|c|c|}
\hline Suggested patient action & Comment \\
\hline $\begin{array}{l}\text { Ask questions and express your values and preferences in regards to } \\
\text { your anticoagulant therapy }\end{array}$ & $\begin{array}{l}\text { Consider all of the possible advantages and disadvantages of DOAC } \\
\text { therapy and choose an anticoagulation regimen that you are most } \\
\text { likely to be adherent with }\end{array}$ \\
\hline $\begin{array}{l}\text { Make sure you are familiar with and understand the DOAC education } \\
\text { provided to you by healthcare staff }\end{array}$ & $\begin{array}{l}\text { If there is something you do not understand or that concerns you, let } \\
\text { the healthcare staff know as soon as possible } \\
\text { Have the healthcare provider give you a safety net phone number to } \\
\text { call in case you have questions at a later time }\end{array}$ \\
\hline $\begin{array}{l}\text { Obtain and wear a Medic Alert bracelet or carry a wallet card stating } \\
\text { you are on anticoagulant }\end{array}$ & $\begin{array}{l}\text { This will notify medical personnel that you are on an anticoagulant in } \\
\text { case you are unable to verbally tell them }\end{array}$ \\
\hline $\begin{array}{l}\text { Follow drug-specific administration and storage recommendations } \\
\text { provided to you }\end{array}$ & e.g. take with food, store in original container, etc. \\
\hline \multicolumn{2}{|l|}{$\begin{array}{l}\text { Establish a set time for taking your DOAC and communicate this to } \\
\text { medical providers, especially in an emergency situations }\end{array}$} \\
\hline \multicolumn{2}{|l|}{$\begin{array}{l}\text { Schedule follow-up phone calls with your anticoagulation provider at } \\
\text { pre-determined times to discuss any issues or difficulties in taking or } \\
\text { refilling your DOAC }\end{array}$} \\
\hline \multicolumn{2}{|l|}{$\begin{array}{l}\text { Make sure you are familiar with both the generic and brand names of } \\
\text { your DOAC and always check your refill for accuracy before leaving } \\
\text { the pharmacy }\end{array}$} \\
\hline $\begin{array}{l}\text { Make sure your anticoagulation provider or another provider is } \\
\text { regularly checking your kidney and liver function to make sure it is } \\
\text { still okay for you to take a DOAC }\end{array}$ & $\begin{array}{l}\text { If you develop kidney or liver problems, let your anticoagulation } \\
\text { provider know as soon as possible }\end{array}$ \\
\hline \multirow{6}{*}{$\begin{array}{l}\text { Go to or participate in all scheduled follow-up visits with your } \\
\text { anticoagulation provider so they can ask you questions that might be } \\
\text { important for safe and effective use of your DOAC }\end{array}$} & What medications have you stopped/started? \\
\hline & What kidney/liver problems have you had? \\
\hline & What side effects have you had from your DOAC? \\
\hline & What problems have you had getting your DOAC refilled? \\
\hline & What extra or missed doses of your DOAC have you had? \\
\hline & What upcoming surgical or dental procedures do you have? \\
\hline
\end{tabular}

DOAC Direct oral anticoagulant

Developing an appreciation for patients' values and preferences is important to determine the best drug therapy option for them and requires a thoughtful, thorough discussion. The DOACs have many advantages and disadvantages (Table 2) that should be reviewed with patients. For example, no requirement for lab monitoring may be perceived as highly beneficial but there may be significant concern about lack of an antidote. Each of these points should be presented to the patient and/or caregiver for consideration, as it may not only influence the choice of anticoagulant, but also adherence to therapy and clinical outcomes [118].

Guidance statement We suggest use of a comprehensive, multi-media educational approach with patients and families to maximize the efficacy and safety associated with anticoagulation in the VTE population. Information should be provided in the patient's preferred language and at an appropriate level of health literacy.

\section{Conclusion}

The arrival of the DOACs has rapidly expanded VTE treatment options over the span of just a few years. While barriers remain for specific segments of the VTE population, the DOACs offer treatment options that are not only more convenient, but likely safer than conventional therapy. Although the DOACs represent a significant advance in VTE treatment, complexity of DOAC dosing regimens, potential for drug interactions, and variable effects on commonly available coagulation assays demand expertise from the prescribing clinician and effective patient education to ensure optimal outcomes for patients treated with 
Table 22 Summary of guidance statements

Question $\quad$ Guidance statement

Which VTE patients are (and are not) good candidates for DOAC therapy?

How should DOACs be initiated for VTE treatment?

How the anticoagulant activity of DOACs be measured?

DOACs are suggested as an alternative to conventional therapy for VTE treatment in patients who meet appropriate patient selection criteria. For all other patients, we suggest VTE treatment with conventional therapy. Until further data are available, we suggest avoiding DOACs for VTE in patients with antiphospholipid antibody syndrome and patients at extremes of weight. LMWH monotherapy remains first line for patients with cancer-related VTE, but DOACs may be considered in select patients unwilling or unable to receive subcutaneous injections

We suggest that a thorough patient evaluation be conducted prior to DOAC initiation which should include assessment of baseline laboratory values, concomitant drug therapies, and comorbidities. We do not recommend initial DOAC therapy in patients who are hospitalized with extensive DVT or who have $\mathrm{PE}$ with hemodynamic instability in whom thrombolysis or thrombectomy may be indicated. We suggest that the unique characteristics of each DOAC, their distinct dosing for VTE treatment, and patient preferences should be considered when selecting a DOAC for VTE treatment

We suggest that clinicians do not routinely measure DOAC activity. If measurement of a DOAC is indicated, we suggest that clinicians use assays that are validated either locally or in a reference laboratory and that are readily available. The chosen assay should be suitable for the DOAC being used, as well as for the indication for measurement, as detailed in Table 6

How should VTE patients who require temporary interruption of DOAC therapy be managed?

For VTE patients on DOAC therapy requiring TI for an invasive procedure, we suggest a carefully constructed, thoughtful approach that emphasizes communication between the provider managing the DOAC therapy, the clinician performing the procedure, and the patient and/or caregiver about the management of the DOAC. If TI is deemed necessary, we suggest that clinicians consider the patient's renal function, the DOAC $\mathrm{t}_{1 / 2}$ and the associated bleeding risk when determining timing of cessation and resumption of the DOAC. We suggest avoiding routine use of bridge therapy during DOAC interruption

How should patients with DOAC drug-drug interactions be managed?

How should patients transition between anticoagulants?

DOAC drug-drug interaction management must be patient-specific and incorporate multiple clinical parameters, such as concomitant renal impairment, extremes of body weight or advanced age. We suggest that clinicians avoid concomitant use of dabigatran and edoxaban with a strong inducer or inhibitor of p-gp and avoid use of rivaroxaban and apixaban with combined strong inducers and inhibitors of p-gp and CYP3A4

For patients requiring concomitant DOAC therapy with a p-gp and/or CYP3A4 inhibitor, we suggest clinicians closely follow the detailed dose adjustments or avoidance provided in the product labeling. We suggest concomitant antiplatelet or NSAIDs be avoided during DOAC therapy unless the potential benefit clearly justifies the increased bleeding risk

Switching from warfarin to a DOAC

When switching from warfarin to dabigatran, apixaban, rivaroxaban or edoxaban, discontinue warfarin and start the DOAC when the International Normalized Ratio (INR) has decreased to $<2$ for dabigatran and apixaban ( $<3$ for rivaroxaban, $<2.5$ for edoxaban) to avoid periods of inadequate or excessive anticoagulation. In cases where the target INR was 2.5-3.5 or higher due to recurrent VTE, initiate the DOAC when the INR is near 2.5 or the lower end of the specified range

Switching from non-warfarin anticoagulant to a DOAC

When switching from a DOAC to a different DOAC or from LMWH/fondaparinux to a DOAC, start the new DOAC 0-2 $\mathrm{h}$ prior to the next scheduled administration of the original anticoagulant and then discontinue the original anticoagulant

When switching from IV UFH to a DOAC, stop the heparin infusion and begin administration of the DOAC at the time of UFH discontinuation

When switching from SC UFH treatment to a DOAC, stop the SC UFH and initiate the DOAC approximately $4-5 \mathrm{~h}$ after the last dose of SC UFH 
Table 22 continued

\begin{tabular}{|c|c|}
\hline Question & Guidance statement \\
\hline How should DOAC-associated bleeding be managed? & $\begin{array}{l}\text { We suggest hospitals develop evidence-based antithrombotic reversal and bleeding } \\
\text { protocols that contain clinical decision support for providers and are easy to } \\
\text { access and use in urgent or emergent situations. We suggest that general } \\
\text { approaches to bleed management be employed for all patients presenting with } \\
\text { severe hemorrhage. For DOAC patients, clinicians should attempt to rapidly } \\
\text { determine time of last DOAC ingestion and patient's renal function to estimate } \\
\text { remaining duration of exposure and potential utility of additional interventions. } \\
\text { Until specific antidotes are available, we suggest clinicians consider use of non- } \\
\text { specific reversal strategies in patient's refractory to standard therapies. For direct } \\
\text { Xa inhibitors, non-activated 4-Factor PCC } 50 \text { units/kg may be considered. For } \\
\text { direct thrombin inhibitors, either } 4 \text {-Factor non-activated PCC } 50 \mathrm{U} / \mathrm{kg} \text { or } \\
\text { activated PCC } 80 \text { U/kg may be considered. However, it is reasonable to withhold } \\
\text { these strategies given the associated thrombosis risk and the low quality of } \\
\text { evidence that they are beneficial in this setting }\end{array}$ \\
\hline $\begin{array}{l}\text { What is an appropriate care transitions and follow-up } \\
\text { strategy for VTE patients on DOAC therapy? }\end{array}$ & $\begin{array}{l}\text { We suggest that hospitals implement systematic DOAC management and } \\
\text { documentation processes that address appropriate patient selection, dose } \\
\text { initiation, perioperative management, switches between anticoagulants and } \\
\text { transitions between care settings. Whenever possible, implementation of a } \\
\text { specialized inpatient and outpatient anticoagulation services is strongly } \\
\text { encouraged. We also strongly recommend that clinicians utilize a DOAC } \\
\text { discharge checklist (Table 18) to ensure all key aspects of patient care and DOAC } \\
\text { therapy are addressed }\end{array}$ \\
\hline $\begin{array}{l}\text { How can patients enhance safety and efficacy of their } \\
\text { DOAC therapy? }\end{array}$ & $\begin{array}{l}\text { We suggest use of a comprehensive, multi-media educational approach with } \\
\text { patients and families to maximize the efficacy and safety associated with } \\
\text { anticoagulation in the VTE population. Information should be provided in the } \\
\text { patient's preferred language and at an appropriate level of health literacy }\end{array}$ \\
\hline
\end{tabular}

DOACs for VTE. Table 22 summarizes these guidance statements.

\begin{abstract}
Acknowledgments We wish to acknowledge the support provided by Myelin and Associates with the preparation of this manuscript for submission. The work contained in this manuscript was partially funded by support from the following companies: Boehringer Ingelheim, Daiichi Sankyo and Janssen Pharmaceuticals. This guidance document is endorsed by the Anticoagulation Forum's Board of Directors: Mark Crowther, MD, MSc, FRCPC, Jack E. Ansell, MD, Allison Burnett, PharmD, Nathan Clark, PharmD, Adam Cuker, MD, David Garcia, MD, Scott Kaatz, DO, MSc, FACP, Renato D. Lopes, MD, PhD, Tracy Minichiello, MD, Edith Nutescu, PharmD, FCCP, Lynn Oertel, MS, ANP, CACP, Eva Kline-Rogers, MS, RN, NP, Terri Schnurr, RN, CCRC, Michael Streiff, MD, Diane Wirth, ANP, CACP, BCPS, CACP, Daniel Witt, Pharm D, Ann Wittkowsky, PharmD, CACP, FASHP, FCCP.
\end{abstract}

\section{Compliance with ethical standards}

Disclosures A Burnett: Nothing to disclose. C Mahan: has received investigator-initiated grants from Sanofi-Aventis and funding from the North American Thrombosis Forum Traveling Fellowship Award, served as a consultant for Point of Care Software Systems, DaiichiSanyko, Sanofi-Aventis, Boehringer Ingelheim, J\&J, Polymedix Inc., Leo, Eisai and New York Hospital Association; served on advisory boards for Daiichi-Sankyo, Janssen, Leo, Eisai, Sanofi, and Phizer; and served as a speaker for Janssen, Bristol Myers Squibb, Pfizer, Sanofi-Aventis, and Boehringer Ingelheim. S Vazquez: no disclosures. L Oertel: Consultant, advisory boards for the following: Boehringer Ingelheim Pharmaceuticals, Inc., Bristol-Myers Squibb Company. National Certification Board for Anticoagulation
Providers, Chairperson of Board Medical and Scientific Advisory Board (MASAB) Member, National Blood Clot Alliance Advisory Council, Anticoagulation Forum. D Garcia: Consultancy for Bristol Meyers Squibb, Daiichi Sankyo, Boehringer Ingelheim, Pfizer, Portola, Janssen, CSL Behring, and Genzyme. Research funding for Bristol Myers Squibb, Daiichi Sankyo, Janssen, and Portola. J Ansell: Consulting activities and/or honoraria from the following companies: Bristol Myers Squibb; Pfizer; Boehringer Ingelheim; Daiichi Sankyo; Janssen; Perosphere; Roche Diagnostics; Alere, Inc; Instrumentation Laboratories. Equity interest in the following companies: Perosphere, Inc.

Open Access This article is distributed under the terms of the Creative Commons Attribution 4.0 International License (http://crea tivecommons.org/licenses/by/4.0/), which permits unrestricted use, distribution, and reproduction in any medium, provided you give appropriate credit to the original author(s) and the source, provide a link to the Creative Commons license, and indicate if changes were made.

\section{References}

1. Van der Hulle T, Kooiman J, den Exter PL et al (2014) Effectiveness and safety of novel oral anticoagulants as compared with vitamin $\mathrm{K}$ antagonists in the treatment of acute symptomatic venous thromboembolism: a systematic review and meta-analysis. J Thromb Haemost 12:320-328. doi:10.1111/jth. 12485

2. Mantha S, Ansell J (2014) Indirect comparison of dabigatran, rivaroxaban, apixaban and edoxaban for the treatment of acute 
venous thromboembolism. J Thromb Thrombolysis. doi:10. 1007/s11239-014-1102-5

3. Schulman S, Kearon C, Kakkar AK et al (2013) Extended use of dabigatran, warfarin, or placebo in venous thromboembolism. N Engl J Med 368:709-718. doi:10.1056/NEJMoa1113697

4. EINSTEIN Investigators, Bauersachs R, Berkowitz SD et al (2010) Oral rivaroxaban for symptomatic venous thromboembolism. N Engl J Med 363:2499-2510. doi:10.1056/NEJMoa1007903

5. Agnelli G, Buller HR, Cohen A et al (2013) Apixaban for extended treatment of venous thromboembolism. N Engl J Med 368:699-708. doi:10.1056/NEJMoa1207541

6. Schulman S, Kearon C, Kakkar AK et al (2009) Dabigatran versus warfarin in the treatment of acute venous thromboembolism. N Engl J Med 361:2342-2352. doi:10.1056/NEJMoa 0906598

7. Schulman S, Kakkar AK, Goldhaber SZ et al (2014) Treatment of acute venous thromboembolism with dabigatran or warfarin and pooled analysis. Circulation 129:764-772. doi:10.1161/ CIRCULATIONAHA.113.004450

8. EINSTEIN-PE Investigators, Büller HR, Prins MH et al (2012) Oral rivaroxaban for the treatment of symptomatic pulmonary embolism. N Engl J Med 366:1287-1297. doi:10.1056/NEJMoa 1113572

9. Agnelli G, Buller HR, Cohen A et al (2013) Oral apixaban for the treatment of acute venous thromboembolism. N Engl J Med 369:799-808. doi:10.1056/NEJMoa1302507

10. Buller FN, Hokusai-VTE Investigators et al (2013) Edoxaban versus warfarin for the treatment of symptomatic venous thromboembolism. N Engl J Med 369:1406-1415. doi:10.1056/ NEJMoa1306638

11. XARELTO-PM-ENG-10JUL2014-172618.pdf. http://www.bayer. ca/files/XARELTO-PM-ENG-10JUL2014-172618.pdf? Accessed 11 Nov 2014

12. Boehringer Ingelheim Canada Ltd (2014) Pradaxa product monograph. http://www.boehringeringelheim.ca/content/dam/ internet/opu/ca_EN/documents/humanhealth/product_monograph/ PradaxaPMEN.pdf. Accessed 11 Nov 2014

13. Bapat P, Kedar R, Lubetsky A et al (2014) Transfer of dabigatran and dabigatran etexilate mesylate across the dually perfused human placenta. Obstet Gynecol 123:1256-1261. doi:10. 1097/AOG.0000000000000277

14. Königsbrügge O, Langer M, Hayde M et al (2014) Oral anticoagulation with rivaroxaban during pregnancy: a case report. Thromb Haemost. doi:10.1160/TH14-04-0393

15. Pfizer Canada Inc Eliquis Product Monograph. http://www.pfi zer.ca/en/our_products/products/monograph/313. Accessed 11 Nov 2014

16. Savaysa Edoxaban PI. http://dsi.com/prescribing-informationportlet/getPIContent?productName=Savaysa\&inline=true. Accessed 22 Sept 2015

17. Stangier DJ, Stähle H, Rathgen K, Fuhr R (2008) Pharmacokinetics and pharmacodynamics of the direct oral thrombin inhibitor dabigatran in healthy elderly subjects. Clin Pharmacokinet 47:47-59. doi:10.2165/00003088-200847010-00005

18. Frost CE, Nepal S, Barrett $Y$ et al (2009) Effects of age and gender on the single-dose pharmacokinetics (PK) and pharmacodynamics (PD) of apixaban. J Thromb Haemost 7(suppl 2): 455

19. Upreti VV, Wang J, Barrett YC et al (2013) Effect of extremes of body weight on the pharmacokinetics, pharmacodynamics, safety and tolerability of apixaban in healthy subjects. Br J Clin Pharmacol 76:908-916

20. Kubitza D, Becka M, Zuehlsdorf M, Mueck W (2007) Body weight has limited influence on the safety, tolerability, pharmakokinetics, or pharmacodynamics of rivaroxaban (BAY 59-7939) in healthy subjects. J Clin Pharmacol 47(2):218-226
21. Schulman S et al (2014) ASH 56th annual meeting San Francisco, CA Dec 2014, session 332 abstract 1544

22. Win K, Rodgers GM (2014) New oral anticoagulants may not be effective to prevent venous thromboembolism in patients with antiphospholipid syndrome. Am J Hematol. doi:10.1002/ajh. 23797

23. Schaefer JK, McBane RD, Black DF et al (2014) Failure of dabigatran and rivaroxaban to prevent thromboembolism in antiphospholipid syndrome: a case series of three patients. Thromb Haemost. doi:10.1160/TH14-03-0272

24. Larsen TB, Nielsen PB, Skjoth F et al (2014) Non-vitamin antagonist oral anticoagulants and the treatment of venous thromboembolism in cancer patients: a semi-systematic review and meta-analysis of safety and efficacy outcomes. PLoS ONE 9:e114445

25. Vedovati MC, Germini F, Agnelli G, Becattini C (2014) Direct oral anticoagulants in patients with venous thromboembolism and cancer: a systematic review and meta-analysis. Chest. doi: $10.1378 /$ chest.14-0402

26. van der Hulle T, den Exter PL, Kooiman J et al (2014) Metaanalysis of the efficacy and safety of new oral anticoagulants in patients with cancer-associated acute venous thromboembolism. J Thromb Haemost 12:1116-1120

27. Sardar P, Chatterjee S, Herzog E et al (2015) New oral anticoagulants in patients with cancer: current state of evidence. Am J Ther 22:460-468

28. Lee AYY, Levine MN, Baker RI et al (2003) Low-molecularweight heparin versus a coumarin for the prevention of recurrent venous thromboembolism in patients with cancer. N Engl J Med 349:146-153. doi:10.1056/NEJMoa025313

29. Meyer G, Marjanovic Z, Valcke J et al (2002) Comparison of low-molecular-weight heparin and warfarin for the secondary prevention of venous thromboembolism in patients with cancer: a randomized controlled study. Arch Intern Med 162(15): 1729-1735

30. Hull RD, Pineo GF, Brant RF, Mah AF, Burke N, Dear R et al (2006) Long-term low-molecular-weight heparin versus usual care in proximal-vein thrombosis patients with cancer. Am J Med 119(12):1062-1072

31. Deitcher SR, Kessler CM, Merli G et al (2006) Secondary prevention of venous thromboembolic events in patients with active cancer: enoxaparin alone versus initial enoxaparin followed by warfarin for a 180 day period. Clin Appl Thromb Hemost 12:389-396

32. Lee A, Kamphuisen PW, Meyer G et al (2015) Tinzaparin vs warfarin for treatment of acute venous thromboembolism in patients with active cancer: a randomized clinical trial. JAMA 314(7):677-686. doi:10.0001/jama.2015.9243

33. Graham DJ, Reichman ME, Wernecke M et al (2015) Cardiovascular, bleeding, and mortality risks in elderly medicare patients treated with dabigatran or warfarin for nonvalvular atrial fibrillation. Circulation 131(2):157-164

34. Sipahi I, Celik S, Tozun N (2014) A comparison of results of the us food and drug administration's mini-sentinel program with randomized clinical trials: the case of gastrointestinal tract bleeding with dabigatran. JAMA Intern Med 174:150-151. doi:10.1001/jamainternmed.2013.12217

35. Chai-Adisaksopha C, Crowther M, Isayama T, Lim W (2014) The impact of bleeding complications in patients receiving target-specific oral anticoagulants: a systemic review and metaanalysis. Blood 124(15):2450-2458

36. Kearon C, Akl EA, Comerota AJ et al (2012) Antithrombotic therapy for VTE disease. Chest 141(2 Suppl):e419S-e494S. doi:10.1378/chest.11-2301

37. Erkens PM, Prins MH (2010) Fixed dose subcutaneous low molecular weight heparins versus adjusted dose unfractionated 
heparin for venous thromboembolism. Cochrane Database Syst Rev 9:CD001100

38. Funk DM (2012) Coagulation assays and anticoagulant monitoring. Hematology 2012:460-465. doi:10.1182/asheducation2012.1.460

39. Tripodi A (2013) The laboratory and the direct oral anticoagulants. Blood 121:4032-4035. doi:10.1182/blood-2012-12-453076

40. Cuker A, Siegal DM, Crowther MA, Garcia DA (2014) Laboratory measurement of the anticoagulant activity of the nonvitamin K oral anticoagulants. J Am Coll Cardiol 64:1128-1139. doi:10.1016/j.jacc.2014.05.065

41. Douketis J (2012) Perioperative management of antithrombotic therapy: antithrombotic therapy and prevention of thrombosis, 9th edn: ACCP. Chest 141:e326S-e350S

42. Healey JS, Eikelboom J, Douketis J et al (2012) Periprocedural bleeding and thromboembolic events with dabigatran compared with warfarin: results from the randomized evaluation of longterm anticoagulation therapy (RE-LY) randomized trial. Circulation 126:343-348. doi:10.1161/CIRCULATIONAHA.111.090464

43. Sherwood MW, Douketis JD, Patel MR et al (2014) Outcomes of temporary interruption of rivaroxaban compared with warfarin in patients with nonvalvular atrial fibrillation: results from the rivaroxaban once daily, oral, direct factor Xa inhibition compared with vitamin $\mathrm{K}$ antagonism for prevention of stroke and embolism trial in atrial fibrillation (ROCKET AF). Circulation 129:18501859. doi:10.1161/CIRCULATIONAHA.113.005754

44. Garcia D, Alexander JH, Wallentin L et al (2014) Management and clinical outcomes in patients treated with apixaban versus warfarin undergoing procedures. Blood 124(25):3692-3698

45. Horlocker TT, Wedel DJ, Rowlingson JC et al (2010) Regional anesthesia in the patient receiving antithrombotic or thrombolytic therapy: American Society of Regional Anesthesia and Pain Medicine Evidence-Based Guidelines (3rd Edition). Reg Anesth Pain Med 35(1):64-101 https://www.ismp.org/news letters/acutecare/issue.aspx?id=82. Accessed 27 Nov 2014

46. Spyropoulos AC, Douketis JD (2012) How I treat anticoagulated patients undergoing an elective procedure or surgery. Blood 120:2954-2962. doi:10.1182/blood-2012-06-415943

47. Baron TH, Kamath PS, McBane RD (2013) Management of antithrombotic therapy in patients undergoing invasive procedures. N Engl J Med 368:2113-2124. doi:10.1056/NEJMra 1206531

48. Wessler JD, Grip LT, Mendell J, Giugliano RP (2013) The P-glycoprotein transport system and cardiovascular drugs. J Am Coll Cardiol 61:2495-2502. doi:10.1016/j.jacc.2013.02.058

49. Gong IY, Kim RB (2013) Importance of pharmacokinetic profile and variability as determinants of dose and response to dabigatran, rivaroxaban, and apixaban. Can J Cardiol 29:S24-33. doi:10.1016/j.cjca.2013.04.002

50. Feinberg J, Grabowitz L, Rotman-Pikielny P et al (2014) Dabigatran etexilate linked to fatal gastrointestinal hemorrhage. Isr Med Assoc 16(6):388-389

51. Lo JC-Y, Gerona RR (2014) A case of rivaroxaban associated intracranial hemorrhage. West J Emerg Med 15:375-377. doi:10.5811/westjem.2014.2.19440

52. Stöllberger C, Zuntner G, Bastovansky A, Finsterer J (2013) Cerebral hemorrhage under rivaroxaban. Int $\mathrm{J}$ Cardiol 167: e179-e181. doi:10.1016/j.ijcard.2013.03.185

53. Fountzilas C, George J, Levine R (2013) Dabigatran overdose secondary to acute kidney injury and amiodarone use. N Z Med J 126:110-112

54. Stöllberger C, Finsterer J (2014) Prolonged anticoagulant activity of rivaroxaban in a polymorbid elderly female with nonconvulsive epileptic state. Heart Lung 43:262-263. doi:10.1016/ j.hrtlng.2014.03.004
55. Marcum ZA, Vande Griend JP, Linnebur SA (2012) FDA drug safety communications: a narrative review and clinical considerations for older adults. Am J Geriatr Pharmacother 10:264271. doi:10.1016/j.amjopharm.2012.05.002

56. Harper P, Young L, Merriman E (2012) Bleeding risk with dabigatran in the frail elderly. N Engl J Med 366:864-866. doi:10.1056/NEJMc1112874

57. Schulman S, Beyth RJ, Kearon C et al (2008) Hemorrhagic complications of anticoagulant and thrombolytic treatment: ACCP evidence-based clinical practice guidelines (8th edn). Chest 133:257S-298S

58. Hankey GJ, Eikelboom JW (2011) Dabigatran etexilate a new oral thrombin inhibitor. Circulation 123:1436-1450. doi:10. 1161/CIRCULATIONAHA.110.004424

59. Liesenfeld K-H, Lehr T, Dansirikul C et al (2011) Population pharmacokinetic analysis of the oral thrombin inhibitor dabigatran etexilate in patients with non-valvular atrial fibrillation from the RE-LY trial. J Thromb Haemost 9:2168-2175. doi:10. 1111/j.1538-7836.2011.04498.x

60. Oldgren J, Budaj A, Granger CB et al (2011) Dabigatran vs. placebo in patients with acute coronary syndromes on dual antiplatelet therapy: a randomized, double-blind, phase II trial. Eur Heart J 32:2781-2789. doi:10.1093/eurheartj/ehr113

61. Mega JL, Braunwald E, Wiviott SD et al (2012) Rivaroxaban in patients with a recent acute coronary syndrome. N Engl J Med 366:9-19. doi:10.1056/NEJMoa1112277

62. Alexander JH, Lopes RD, James S et al (2011) Apixaban with antiplatelet therapy after acute coronary syndrome. N Engl J Med 365:699-708. doi:10.1056/NEJMoa1105819

63. Davidson BL, Verheijen S, Lensing AA et al (2014) Bleeding risk of patients with acute venous thromboembolism taking nonsteroidal anti-inflammatory drugs or aspirin. JAMA Intern Med 174:947-953. doi:10.1001/jamainternmed.2014.946

64. Patel MR, Mahaffey KW, Garg J et al (2011) Rivaroxaban versus warfarin in nonvalvular atrial fibrillation. $\mathrm{N}$ Engl $\mathrm{J}$ Med 365:883-891. doi:10.1056/NEJMoa1009638

65. Granger CB, Alexander JH, McMurray JJV et al (2011) Apixaban versus warfarin in patients with atrial fibrillation. N Engl J Med 365:981-992. doi:10.1056/NEJMoa1107039

66. Abo-Salem E, Becker R (2014) Transitioning to and from the novel oral anticoagulants: a management strategy for clinicians. J Thromb Thrombolysis 37:372-379. doi:10.1007/s11239-0141060-y

67. Atay JK, Fanikos J, Barnes GD et al (2013) Effect of dabigatran on referrals to and switching from warfarin in two academic anticoagulation management services. Am J Cardiol 112:387389. doi:10.1016/j.amjcard.2013.03.046

68. Pottegård A, Poulsen BK, Larsen MD, Hallas J (2014) Dynamics of vitamin $\mathrm{K}$ antagonist and new oral anticoagulants use in atrial fibrillation: a Danish drug utilization study. J Thromb Haemost 12:1413-1418

69. Connolly SJ, Ezekowitz MD, Yusuf S et al (2009) Dabigatran versus warfarin in patients with atrial fibrillation. N Engl J Med 361:1139-1151. doi:10.1056/NEJMoa0905561

70. Giugliano RP, Ruff CT, Braunwald E et al (2013) Edoxaban versus warfarin in patients with atrial fibrillation. $\mathrm{N}$ Engl $\mathrm{J}$ Med 369:2093-2104. doi:10.1056/NEJMoa1310907

71. Majeed A, Hwang H-G, Connolly SJ et al (2013) Management and outcomes of major bleeding during treatment with dabigatran or warfarin. Circulation 128:2325-2332. doi:10.1161/CIR CULATIONAHA.113.002332

72. Piccini JP, Garg J, Patel MR et al (2014) Management of major bleeding events in patients treated with rivaroxaban vs. warfarin: results from the ROCKET AF trial. Eur Heart J 35:1873-1880. doi:10.1093/eurheartj/ehu083 
73. Hylek E, Held C, Alexander JH et al (2014) Major bleeding in patients with atrial fibrillation receiving apixaban or warfarin: the ARISTOTLE trial: predictors, characteristics, and clinical outcomes. J Am Coll Cardiol 63:2141-2147

74. Research C for DE and drug safety and availability-FDA Drug Safety Communication: FDA study of medicare patients finds risks lower for stroke and death but higher for gastrointestinal bleeding with Pradaxa (dabigatran) compared to warfarin. http:// www.fda.gov/drugs/drugsafety/ucm396470.htm. Accessed 27 Nov 2014

75. Siegal DM, Cuker A (2014) Reversal of target-specific oral anticoagulants. Drug Discov Today. doi:10.1016/j.drudis.2014. 05.013

76. Van Ryn J, Schurer J, Kink-Eiband M, Clemens A (2011) The successful reversal of dabigatran-induced bleeding by coagulation factor concentrates in a rat tail bleeding model do not correlate with ex vivo markers of anticoagulation. Blood 118(21):1004

77. Van Ryn J et al (2008) 13th congress of the European Hematology Association, Copenhagen, Denmark, June 12-15, 2008. Haematologica 93(s-1):148

78. Pragst I, Zeitler SH, Doerr B, Kaspereit FJ, Herzog E, Dickneite $G$ et al (2012) Reversal of dabigatran anticoagulation by prothrombin complex concentrate (Beriplex $\mathrm{P} / \mathrm{N})$ in a rabbit model. J Thromb Haemostas 10(9):1841-1848

79. Martin AC, LeBonniec B, Fischer AM (2013) Evaluation of recombinant activated factor VII, prothrombin complex concentrate, and fibrinogen concentrate to reverse apixaban in a rabbit model of bleeding and thrombosis. $\mathbf{J}$ Int Card 168(4):4228-4233. doi:10.1016/j.ijcard.2013.07.152

80. Perzborn E, Gruber A, Tinel H et al (2013) Reversal of rivaroxaban anticoagulation by haemostatic agents in rats and primates. Thromb Haemost 110(1):162-172

81. Zahir H, Brown KS, Vandell AG et al (2015) Edoxaban effects on bleeding following punch biopsy and reversal by a 4-factor prothrombin complex concentrate. Circulation 131:82-90

82. Godier A, Miclot A, LeBonniec B, Durand M, Fischer A-M, Emmerich $\mathbf{J}$ et al (2012) Evaluation of prothrombin complex concentrate and recombinant activated factor VII to reverse rivaroxaban in a rabbit model. Anesthesiology 116(1):94-102

83. Marlu R, Hodaj E, Paris A et al (2012) Effect of non-specific reversal agents on anticoagulant activity of dabigatran and rivaroxaban: a randomized crossover ex vivo study in healthy volunteers. Thromb Haemost 108:217-247

84. Eerenberg ES, Kamphuisen PW, Sijpkens MK et al (2011) Reversal of rivaroxaban and dabigatran by prothrombin complex concentrate: a randomized, placebo-controlled, crossover study in healthy subjects. Circulation 1214:1573-1579

85. Dager WE, Gosselin RC, Roberts AJ et al (2013) Reversing dabigatran in life-threatening bleeding occurring during cardiac ablation with factor eight inhibitor bypassing activity. Crit Care Med 41(5):42-46

86. Dentali F, Marchesi C, Pierfranceschi MG et al (2011) Safety of prothrombin complex concentrates for rapid anticoagulation reversal of vitamin $\mathrm{K}$ antagonists: a meta-analysis. Thromb Haemost 106:429-438. doi:10.1160/TH11-01-0052

87. Levi M, Levy JH, Andersen HF, Truloff D (2010) Safety of recombinant activated factor VII in randomized clinical trials. N Engl J Med 363:1791-1800. doi:10.1056/NEJMoa1006221

88. Siegal DM, Garcia DA, Crowther MA (2014) How I treat targetspecific oral anticoagulant-associated bleeding. Blood 123: 1152-1158. doi:10.1182/blood-2013-09-529784

89. Kaatz S, Kouides PA, Garcia DA et al (2012) Guidance on the emergent reversal of oral thrombin and factor Xa inhibitors. Am J Hematol 87:S141-S145. doi:10.1002/ajh.23202
90. Kaatz S, Crowther M (2013) Reversal of target-specific oral anticoagulants. J Thromb Thrombolysis 36:195-202. doi:10. 1007/s11239-013-0923-y

91. van Ryn J et al (2014) American Heart Association Scientific Sessions 2014, Chicago, USA. http://www.abstractsonline.com/ pp8/\#!/3547/presentation/41579

92. Glund S (2013) 17765-A specific antidote for dabigatran: immediate, complete and sustained reversal of dabigatran induced anticoagulation in healthy male volunteers. Paper presented at the American Heart Association Scientific Sessions, Dallas, Texas, 16-20 November 2013

93. NCT02104947 clinicaltrials.gov

94. Hutchchaleelaha A et al (2012) European society of cardiology annual meeting. Munich, Germany 27

95. Lu G, DeGuzman FR, Hollenbach SJ et al (2013) A specific antidote for reversal of anticoagulation by direct and indirect inhibitors of coagulation factor Xa. Nat Med 19(4):446-451

96. Crowther M; ASH 2014 San Francisco abstract \#4269 Session 332. antithrombotic therapy: poster III Monday, December 8

97. Crowther M, et al; ASH 2013. Abstract 3636, session 332. antithrombotic therapy: poster III Monday, December 9, 2013

98. Crowther M, et al. ISTH 2013 Amsterdam

99. A study in older subject to evaluate the safety and ability of andexanet alfa to reverse the anticoagulation effect of rivaroxaban-full text view-ClinicalTrials.gov. http://clinicaltrials. gov/ct2/show/NCT02220725?term $=$ NCT02220725\&rank $=1$. Accessed 27 Nov 2014

100. A study in older subjects to evaluate the safety and ability of andexanet alfa to reverse the anticoagulation effect of apixaban-full text view-ClinicalTrials.gov. http://clinicaltrials. gov/ct $2 /$ show $/$ NCT02207725?term $=$ NCT02207725\&rank $=1$. Accessed 27 Nov 2014

101. Laulicht B, Bakhru S, Jiang X, et al (2013) Antidote for new oral anticoagulants: mechanism of action and binding specificity of PER977. Presented at the 24th congress of the international society on thrombosis and haemostasis, Amsterdam, June 29July 4, 2013. Abstract (http://www.eventure-online.com/enen ture/publicAbstractView.do?id=2267118\&congressId=6839

102. Ansell JE, Bakhru S, Laulicht BE, Steiner SS, Grosso M, Brown K, Dishy V, Noveck RJ (2014) Use of PER977 to reverse the anticoagulant effect of edoxaban. N Eng J Med 371:2141-2142

103. Pollack CV Jr, Reilly PA, Eikelboom J et al (2015) Idarucizumab for Dabigatran Reversal. N Engl J Med 373(6): 511-520. doi:10.1056/NEJMoa1502000

104. Crowther MA, et al (2015) ISTH Congress 2015 abstract LB004

105. Burton R (2012) Improving care transitions. Robert Wood Johnson Foundation Health Policy Brief Sept 13, 2012. www. rwjf.org/content/dam/farm/reports/issue_briefs/2012/rwjf401314

106. Schillig J, Kaatz S, Hudson M et al (2011) Clinical and safety impact of an inpatient pharmacist-directed anticoagulation service. J Hosp Med 6:322-328. doi:10.1002/jhm.910

107. Makowski CT, Jennings DL, Nemerovski CW et al (2013) The impact of pharmacist-directed patient education and anticoagulant care coordination on patient satisfaction. Ann Pharmacother 47:805-810. doi:10.1345/aph.1R686

108. Spyropoulos AC, Viscusi A, Singhal N et al (2014) Features of electronic health records necessary for the delivery of optimized anticoagulant therapy consensus of the EHR Task Force of the New York State Anticoagulation Coalition. Ann Pharmacother. doi: $10.1177 / 1060028014555176$

109. Cowell RPW (2014) Direct oral anticoagulants: integration into clinical practice. Postgrad Med J 90:529-539. doi:10.1136/post gradmedj-2013-132474

110. Michota F (2013) Transitions of care in anticoagulated patients. J Multidiscip Healthc 6:215-228. doi:10.2147/JMDH.S44068 
111. Spyropoulos AC, Kardos J, Wigal P (2000) Outcome analyses of the outpatient treatment of venous thromboemolic disease using the low-molecular-weight heparin enoxaparin in a managed care organization. J Manag Care Pharm 6:298-304

112. Jiménez D, Aujesky D, Moores L et al (2010) Simplification of the pulmonary embolism severity index for prognostication in patients with acute symptomatic pulmonary embolism. Arch Intern Med 170:1383-1389. doi:10.1001/archinternmed.2010. 199

113. Heidbuchel H, Verhamme P, Alings M et al (2013) European Heart Rhythm Association Practical Guide on the use of new oral anticoagulants in patients with non-valvular atrial fibrillation. Europace 15:625-651. doi:10.1093/europace/eut083

114. James, J (2013) patient engagement. In: Health affairs. http:// www.healthaffairs.org/healthpolicybriefs/brief.php?brief_id=86. Accessed 27 Nov 2014

115. Hibbard JH, Greene J, Overton V (2013) Patients with lower activation associated with higher costs; delivery systems should know their patients' "Scores". Health Aff 32:216-222. doi:10. 1377/hlthaff.2012.1064

116. Johnson A, Sandford J, Tyndall J (2003) Written and verbal information versus verbal information only for patients being discharged from acute hospital settings to home. Cochrane Database Syst Rev. doi:10.1002/14651858.CD003716

117. Institute for Safe Medication Practices (ISMP) (2003) https:// www.ismp.org/Survey/surveyresults/NursingSurvey.asp. Accessed 27 Nov 2014

118. Ageno W, Crowther M, Baglin T, Falanga A, Buller H, Palareti $\mathrm{G}$ et al (2013) Selection and assessment of patients treated with the novel oral anticoagulant drugs: a recommendation from the Subcommittee on Control of Anticoagulation of the Scientific and Standardisation Committee of the International Society on Thrombosis and Haemostasis. J Thromb Haemost 11(1): 177-179

119. Bauer KA (2013) Pros and cons of new oral anticoagulants. Hematol Am Soc Hematol Educ Program 2013:464-470. doi:10. 1182/asheducation-2013.1.464

120. Cushman M (2013) Treating acute venous thromboembolismshift with Care. N Engl J Med 369(9):865-866

121. Thachil J (2014) The newer direct oral anticoagulants: a practical guide. Clin Med 14:165-175. doi:10.7861/clinmedicine.142-165

122. Weitz JI, Gross PL (2012) New oral anticoagulants: which one should my patient use? Hematology 2012:536-540. doi:10. 1182/asheducation-2012.1.536

123. Schulman S (2014) New oral anticoagulant agents-general features and outcomes in subsets of patients. Thromb Haemost 111(4):575-582

124. Mahan CE, Spyropoulos AC, Fisher MD et al (2013) Antithrombotic medication use and bleeding risk in medically ill patients after hospitalization. Clin Appl Thromb Hemost 19:504-512. doi:10.1177/1076029612470967

125. Decousus H, Tapson VF, Bergmann J-F et al (2011) Factors at admission associated with bleeding risk in medical patients: findings from the improve investigators. Chest 139:69-79. doi:10.1378/chest.09-3081

126. IPRO MAPP tool. http://qio.ipro.org/wp-content/uploads/2012/ 12/MAP2014_5_01.pdf

127. Kaatz S, Mahan CE (2014) Stroke prevention in patients with atrial fibrillation and renal dysfunction. Stroke 45:2497-2505. doi:10.1161/STROKEAHA.114.005117

128. Lippi G, Favaloro EJ, Mattiuzzi C (2014) Combined administration of antibiotics and direct oral anticoagulants: a renewed indication for laboratory monitoring. Semin Thromb Hemost 40:756-765

129. Wang L, Zhang D, Raghavan N et al (2010) In vitro assessment of metabolic drug-drug interaction potential of apixaban through cytochrome $\mathrm{P} 450$ phenotyping, inhibition, and induction studies. Drug Metab Dispos 38:448-458

130. Härtter S, Koenen-Bergmann M, Sharma A et al (2012) Decrease in the oral bioavailability of dabigatran etexilate after co-medication with rifampicin. $\mathrm{Br} \mathrm{J}$ Clin Pharmacol 74:490-500. doi:10.1111/j.1365-2125.2012.04218.x

131. Kishimoto W, Ishiguro N, Ludwig-Schwellinger E et al (2014) In vitro predictability of drug-drug interaction likelihood of P-glycoprotein-mediated efflux of dabigatran etexilate based on [I]2/IC50 threshold. Drug Metab Dispos 42:257-263. doi:10. 1124/dmd.113.053769

132. Mendell J, Zahir H, Matsushima N et al (2013) Drug-drug interaction studies of cardiovascular drugs involving P-glycoprotein, an efflux transporter, on the pharmacokinetics of edoxaban, an oral factor Xa inhibitor. Am J Cardiovasc Drugs 13:331-342. doi:10.1007/s40256-013-0029-0

133. Delavenne X, Ollier E, Basset T et al (2013) A semi-mechanistic absorption model to evaluate drug-drug interaction with dabigatran: application with clarithromycin. $\mathrm{Br} \mathrm{J}$ Clin Pharmacol 76(1):107-113. doi:10.1111/bcp.12055

134. Hansten PD, Horn JR (2012) The top 100 drug interactions: a guide to patient management, 2012th edn. Freeland, WA

135. FDA document: drug interactions and labeling $>$ drug development and drug interactions: table of substrates, inhibitors, and inducers. http://www.fda.gov/drugs/developmentapproval process/developmentresources/druginteractionslabeling/ucm093 664.htm

136. Risselada AJ, Visser MJ, van Roon EN (2013) Pulmonary embolism due to interaction between rivaroxaban and carbamazepine. Ned Tijdschr Geneeskd 157:A6568

137. Altena R, van Roon E, Folkeringa R et al (2014) Clinical challenges related to novel oral anticoagulants: drug-drug interactions and monitoring. Haematologica 99:e26-e27. doi:10. 3324/haematol.2013.097287

138. Mueck W, Kubitza D, Becka M (2013) Co-administration of rivaroxaban with drugs that share its elimination pathways: pharmacokinetic effects in healthy subjects. Br J Clin Pharmacol 76:455-466. doi:10.1111/bcp. 12075

139. Gnoth MJ, Buetehorn U, Muenster U et al (2011) In vitro and in vivo P-glycoprotein transport characteristics of rivaroxaban. J Pharmacol Exp Ther 338:372-380. doi:10.1124/jpet.111.180240 